\title{
INSCRIPCIONES HONORÍFICAS DEL TEATRO DE CARTHAGO NOVA*
}

\author{
POR \\ SEBASTIÁN F. RAMALLO ASENSIO \\ Departamento de Prehistoria, Arqueología, Historia Antigua y Medieval \\ Universidad de Mucia \\ RESUMEN
}

En este trabajo se analizan tres inscripciones conmemorativas halladas en el teatro romano de Cartagena en 1990. Dos de ellas se inscriben sobre sendas arae de mármol blanco, mientras que la tercera corresponde a un gran dintel horizontal. Representan una exaltación a la figura de Gaius Caesar, posible patrono de la ciudad.

\section{SUMMARY}

In this paper three monumental commemorative inscriptions, discovered during excavations at the Roman Theatre in Carthagena (Spain) in 1990, are studied. Two are cut on altars of white marble and the third on a very broad lintel, and all three honour the figure of Gaius Caesar, possible patron of the city.

\section{ANTECEDENTES Y CIRCUNSTANCIAS DEL HALLAZGO.}

Las inscripciones y los materiales objeto de estudio en este trabajo han sido hallados en la ladera occidental del Cerro del Castillo de la Concepción, el antiguo mons Aesculapii en la detallada descripción polibiana de la topografía cartagenera (Pol. X,10,l). Desde el punto de vista

* Agradecemos las sugerencias y comentarios de nuestros compañeros y colegas, doctores J. M. Abascal, F. Moya del Baño y M. Mayer, que han contribuido notablemente a enriquecer el contenido de esta nota preliminar. 
arqueológico, dadas las especiales condiciones naturales de este Cerro, el más elevado y de mayores dimensiones de los cinco que constituyen la ciudad antigua, el área comprendida en el entorno de la Catedral Vieja había proporcionado numerosos restos arquitectónicos, pavimentos e inscripciones que hacían denotar la existencia de un importante complejo monumental en sus alrededores '. Estas previsiones se han visto confirmadas tras las excavaciones arqueológicas que desde finales de 1988 hemos venido realizando de forma sistemática en lo que se conoce oficialmente como solares del entorno de la Plaza de la Condesa de Peralta, junto a la mencionada Catedral Vieja y en la ladera occidental de dicho Cerro. Por su proximidad al puerto, ésta ha sido tradicionalmente una de las zonas más densamente pobladas de la ciudad, y hasta no hace muchos años uno de sus centros neurálgicos, pero la progresiva degradación a que se ha visto sometido el casco antiguo y el consiguiente desplazamiento de la población con mayores recursos hacia las nuevas zonas del ensanche de la ciudad, que en gran parte han venido a ocupar los terrenos colmatados del viejo Almarjal, ha provocado un paulatino deterioro de viviendas y calles y la progresiva ruina de muchos de sus edificios. Este fenómeno precisamente, al tiempo que ha facilitado los trabajos de excavación, paralelamente ha sido también un freno a su desarrollo en extensión dada la excesiva parcelación del suelo que ha provocado la existencia de solares de dimensiones muy reducidas y distintos propietarios, así como una difícil actuación al existir incluso también en algunos casos, riesgo de desplome de las edificaciones colindantes. Pero al mismo tiempo esta misma situación podrá facilitar la actuación futura al tratarse de solares y viviendas de bajo precio y al no existir grandes bolsas de población que deban ser realojadas, ya que son muy pocas las familias que en la actualidad habitan en la zona que podemos considerar se halla dentro del complejo monumental.

En todo este contexto, y tras un primer sondeo efectuado a finales de $1987^{2}$, en noviembre de 1988 se iniciaron las excavaciones sistemáticas que se prolongaron, de forma discontinua, hasta marzo de 1989. Una segunda fase de actuación se desarrolló entre los meses de enero y marzo de 1990, reanudándose de nuevo en octubre del mismo año y finalizando en marzo de 1991. La entidad de los restos y la necesidad de abordar su excavación de forma extensiva, acometiendo el estudio de todo el conjunto han determinado la paralización de los trabajos de campo, mientras que se procede a la adquisición y derribo de edificios y solares afectados por la excavación y se elabora un proyecto definitivo de replanteamiento urbanístico para toda la zona.

' Los hallazgos antiguos de todo el entorno del Castillo de la Concepcion fueron en parte recogidos por Beltrán, A.: "El plano arqueológico de Cartagena", en AEspA., XXV, 1952, 47-82 y especialmente en las páginas 66-70, destacando sobre todo las "lápidas conmemorativas y fragmentos de construcciones monumentales" que hacían concluir a este autor la existencia en esta zona del "templo de la Salud, el de Augusto y el Circo" (este último hoy ya definitivamente identificado con el anfiteatro de la ciudad). Otros hallazgos posteriores del entorno de la Catedral Vieja han sido inventariados recientemente por San Martín, P.: «Nuevas aportaciones al plano arqueológico de Cartagena», Boletín del Museo de Zaragoza, 4, 1985, 131-149.

${ }^{2}$ Este primer sondeo fue realizado dentro del programa de excavaciones de urgencia del Museo Arqueológico Municipal de Cartagena por la licenciada en H. ${ }^{a}$ Antigua y Arqueología, Dña. María del Carmen Berrocal Caparrós. Debo agradecer aquí la amable invitación de D. Pedro A. San Martín Moro, director del Museo Municipal de Cartagena y responsable junto al Dr. Martínez Andreu de las excavaciones de urgencia en la ciudad, para la realización de las excavaciones en la zona. 


\section{DESCRIPCIÓN DEL HALLAZGO}

El yacimiento ha proporcionado una amplia y compleja secuencia estratigráfica que abarca desde los niveles más recientes, de los siglos XVIII y XIX, que con sus cimentaciones y pozos ciegos han alterado y en parte destruido estructuras y depósitos antiguos, pasando por un sector de habitación de época islámica, situado en el sector Suroeste de la excavación y un importante complejo comercial de época tardo-romana y bizantina (ss. V-VII), que se superpone y en parte reutiliza las construcciones monumentales del viejo teatro construidas, como veremos más adelante, en época augustea ${ }^{3}$. Se observa así cómo en el espacio comprendido entre el gran pa-

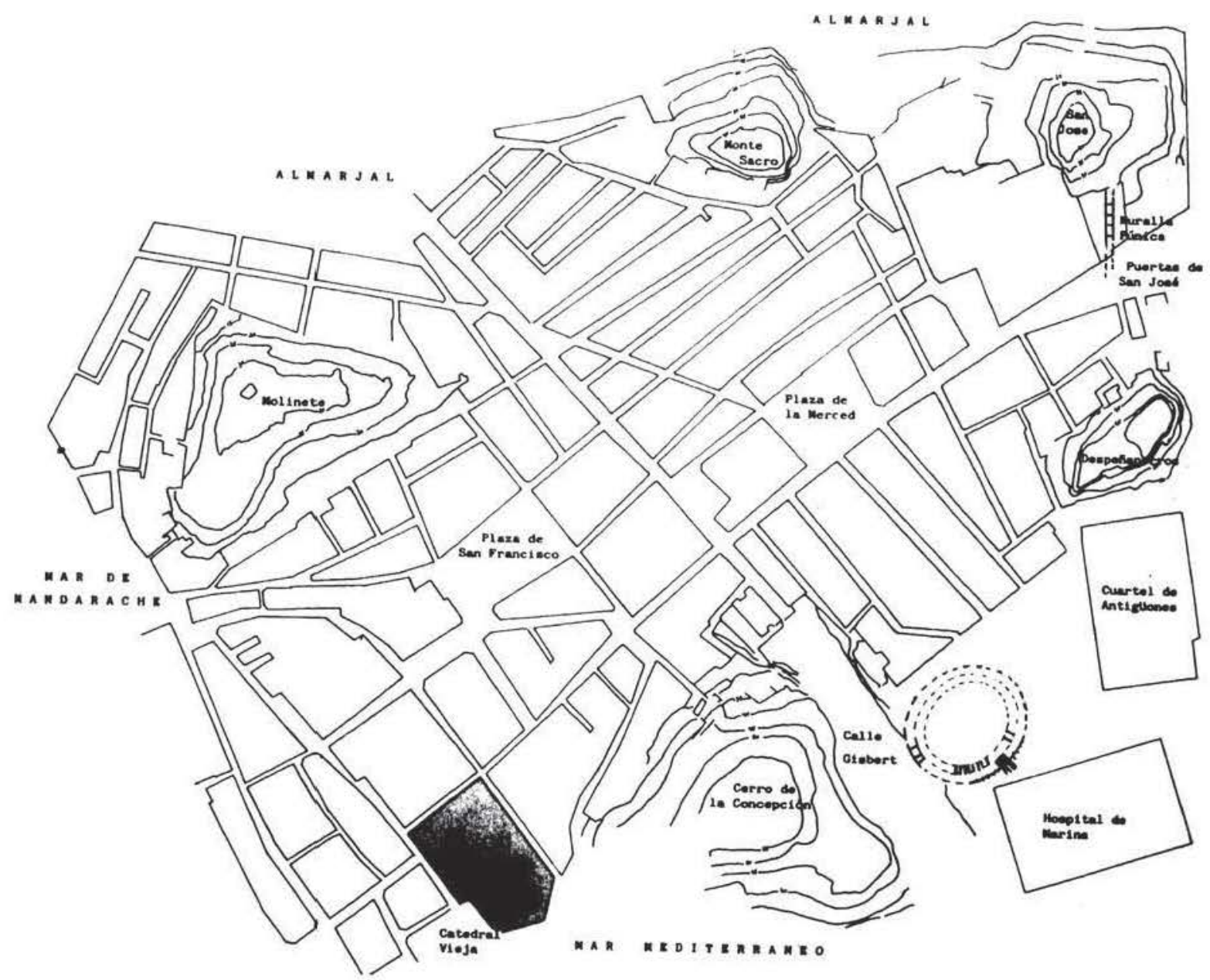

Fig. 1. Ubicación de la zona de los hallazgos en la ladera occidental del Castillo de la Concepción, junto a las ruinas de la Catedral Vieja.

\footnotetext{
${ }^{3}$ Los primeros avances sobre los resultados de la excavación han sido oportunamente remitidos a la Dirección General de Cultura de la Comunidad Autónoma para su publicación en las Memorias de actuación del citado organismo (vid. Ramallo, S., Berrocal, M. C. y Laiz, M. D.: «Informe sobre las excavaciones arqueológicas realizadas en el solar de la Casa-Palacio de la Condesa de Peralta (Cartagena)», Memorias de Arqueología, 1989 (en prensa), y un primer avance de los materiales de época tardía se pre-
} 
ramento de la escena formado por una cimentación maciza de algo más de 7 metros de anchura y una profundidad media de 4 metros, y el inicio de la carea y orchestra se distribuyen una serie de habitaciones alineadas, a modo de tahernae de 2,5 metros de anchura y 7 metros de longitud, en cuyas cimentaciones, destinadas a salvar el foso de hyposcaenium y de casi 2 metros de profundidad, se utilizó abundante material arquitectónico y ornamental amortizado (capiteles, basas, cornisas, fustes de columna, etc.) perteneciente al propio teatro. Destaca, entre todo este material, un lote de 13 capiteles corintios de mármol blanco cuyas características esenciales destacamos más abajo. Pero también en el relleno de colmatación bajo las habitaciones tardorromanas y entremezclado con grandes sillares de arenisca y otros elementos constructivos. fueron halladas las dos aras conmemorativas con inscripción que constituyen el núcleo central de este trabajo (figs. 2 y 3). La tercera inscripción que analizamos, asimismo de carácter conmemorativo, constituía el dintel rectangular situado sobre uno de los itinera de acceso a la $\mathrm{or}$ chestra. Siguiendo un orden cronológico en cuanto a la fecha de aparición de los diferentes testimonios epigráficos, comenzamos por la última mencionada.

Inscripción núm. 1 (figs. 4 y 5 )

Inscripción conmemorativa grabada sobre un dintel incompleto de piedra caliza gris ${ }^{4}$ de 0 ' 84 $\mathrm{m}$. de ancho $\times 2{ }^{\prime} 4 \mathrm{~m}$. de longitud y 0’38 m. de profundidad. Se halla partida en dos trozos que miden respectivamente 1'81 m. y 1'13 m. Fue hallada el 26 de enero de 1990 desplomada sobre el pavimento de opus signinum liso de uno de los itinera con el fragmento de menores dimensiones vuelto al revés. Se conserva actualmente in situ. Letra de tipo capital cuadrado de excelente factura y surcos profundos, con puntos triangulares invertidos de interpunción y una altura constante de $18^{\prime} 5 / 19 \mathrm{cms}$. excepto en la T de augusti que mide $22 \mathrm{cms}$. y las dos I de divi cuya altura es de $21^{\prime} 5 \mathrm{cms}$. La zona de escritura conservada, ligeramente rehundida, es un rectángulo horizontal de 2’14 m. x 3’45 m. y se halla delimitado por un marco de doble moldura cóncava. l.a parte superior del sillar se remata con una moldura sobresaliente suavemente articulada. Ciera la inscripción por su lado derecho (y seguramente también por el izquierdo aunque este lado no se haya localizado hasta el momento) un cuerpo rectangular liso de $48 \mathrm{cms}$. de ancho por 82 cms. de altura. El texto dice: C(aio). Caes]ARI.AVGVSTI.F(ilio).DIVI.N(epoti). La restitución del fragmento que falta (fig. 5) nos parece confirmada por la leyenda epigráfica de las dos aras de mármol que analizamos a continuación.

sentó al Congreso de visigodos celebrado en Madrid en 1990, con el título Carthago Spartaria. La ciudad entre los siglos IV y VII d. C.

${ }^{4}$ En realidad se trata de una de las típicas micritas grisáceas procedentes de las canteras del Sabinal y los Nietos, situadas unos pocos kms. al este de Carthago Nova que fueron ampliamente utilizadas en inscripciones, elementos arquitectónicos y constructivos, etc. Vid. Ramallo, S. y Arana, R.: Canteras romanas de Carthago Nova y alrededores, Murcia, 1987, especialmente pp. 90-93. 

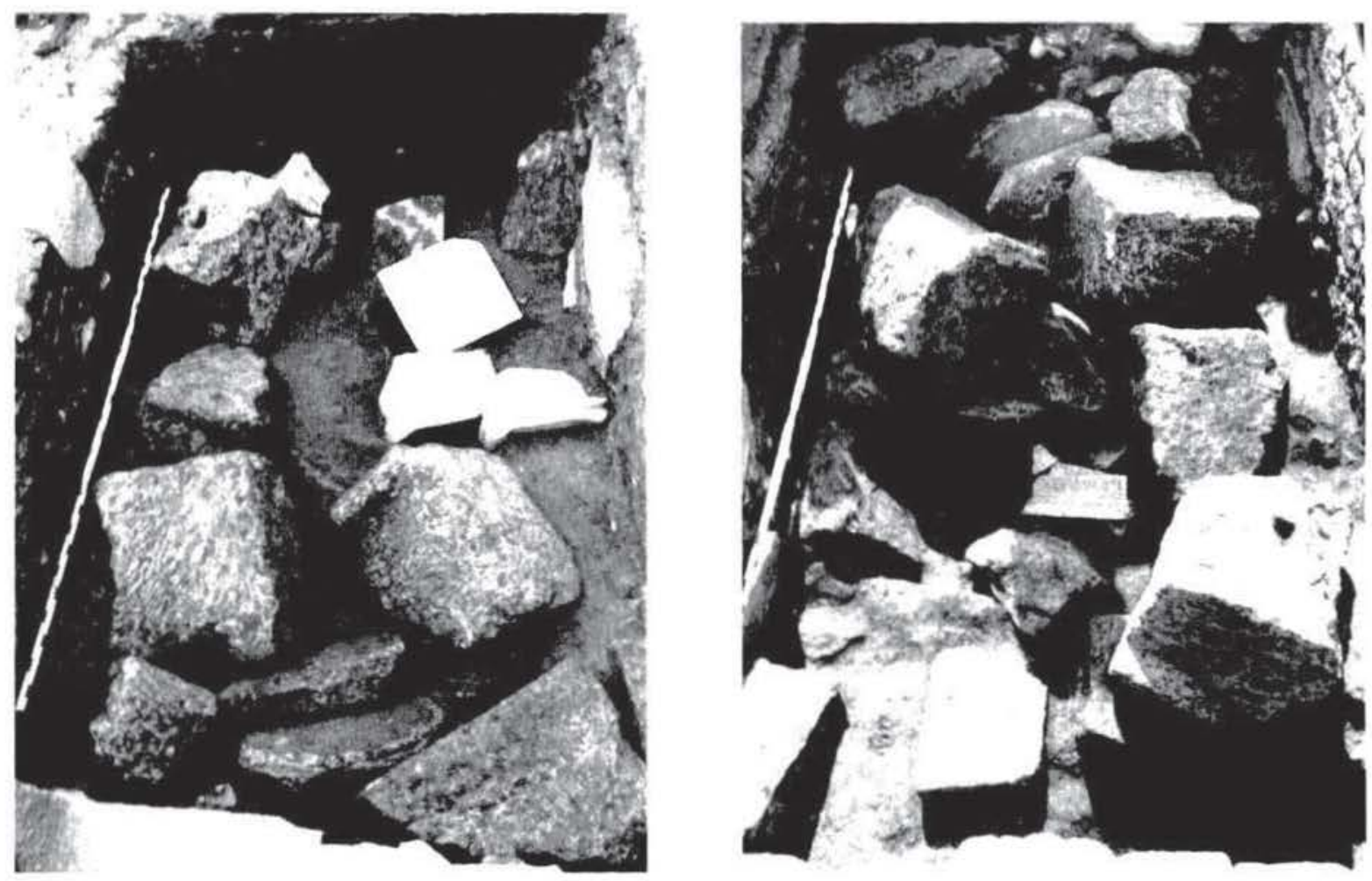

Figs. 2 y 3.-Taberna 1-3, momento del hallazgo de las aras en el relleno intencionado de colmatacion.

Inscripción mim. 2 (figs. 2,7 y 8 )

Ara votiva de mármol blanco hallada fragmentada el 13 de marzo de 1990 en el relleno de la taberna tardo-romana 1-3. Hasta el momento se conserva tan sólo aproximadamente el tercio superior que incluye completos en su cara anterior campo epigráfico, cimacio y pulvino. Las medidas máximas de lo conservado son $58 \mathrm{cms}$. de ancho x $36 \mathrm{cms}$. de altura y $21^{\prime} 7 \mathrm{cms}$. de profundidad. La letra es capital cuadrada. El campo epigráfico mide $20^{\circ} 6 \mathrm{cms}$. de altura $43 \mathrm{cms}$. de ancho y se inserta en un cuerpo rectangular de $46 \mathrm{cms}$. de anchura y de 24 ' $5 \mathrm{cms}$. de altura (conservada). Sobre él una moldura formada, de abajo a arriba, por caveto, doble listel, gola recta, listel y gola reversa. Por encima del ábaco rectangular se desarrolla un cimacio liso con pulvinos laterales decorados con hojas imbricadas con nervadura central y pequeñas cabezas de gorgona en el frente encuadradas en un doble anillo. Las medidas de los renglones son $1.1 .3 .5 \mathrm{cms}$.: 1.2, 3’15 cms.; 1.3: $2^{\prime} 9 \mathrm{cms}$.; 1.4: $2{ }^{\prime} 7 \mathrm{cms}$. Los espacios entre líneas son: de 1'7 cms. entre 1.1 y $1.2 ; 1.5 \mathrm{cms}$. entre 1.2 y 1.3 y $1{ }^{\prime} 5 \mathrm{cms}$. entre 1.3 y 1.4 . Presenta interpunciones en forma de triángulo invertido en todas sus líneas, forma de separación caracteristica de finales del siglo I a.C. y del primer cuarto del siglo I d.C. En la paginación se observa un cierto desplazamiento del texto hacia la izquierda, así en $1.1,1-1$ ' $8 \mathrm{cms}$. En cualquier caso, y pese al estado fragmentado de la 
inscripción llama la atención la distribución de la leyenda en 1.4, donde nombre y filiación del dedicante se inician casi en el ángulo del ara, y se juntan más las letras como queriendo reservar espacio en la derecha para tres/cuatro letras más, que muy bien podrían corresponder bien a algún cargo o magistratura ostentada por el personaje o bien a la abreviatura de la consagración del ara. Se conserva actualmente en el Museo Arqueológico Municipal de Cartagena. El texto dice:

C.CAESARIS·AVGVSTIF $F($ ilii)

PONTIF(icis) $\cdot C O(n) S($ ulis) $\cdot$ DESIG(nati)

PRINCIPIS.IVVENTVTIS

[L·IV]NIVS L L(ucii) $\cdot F($ ilius $) \cdot T($ iti $) \cdot N($ epos $) \cdot P A E T V S \cdot[S A C($ rum $)]$

[D(onum) $] \cdot D$ (edit o Dedicavit)

Inscripción núm. 3 (figs. 3,9 y 10)

Ara votiva de mármol blanco hallada junto a la anterior el 13 de marzo de 1990 en el relleno de la taherna tardo-romana 1-3. Ha perdido tan sólo el ángulo posterior derecho. Está formada por un cuerpo central prismático levantado sobre pedestal y coronado por una moldura con ábaco, cimacio y pulvino. Sus dimensiones son: $64^{\prime} 5 \times 50 \times 50^{\prime} 6 \mathrm{cms}$ de profundidad en el cuerpo central, en el cual el campo epigráfico ocupa 46' 6 × $15 \mathrm{cms}$.; el ábaco mide $2^{\prime} 9 \mathrm{cms}$., mientras que el cimacio tiene una altura de $7^{\prime} 8 \mathrm{cms}$., siendo el diámetro del extremo circular del pulvino donde se reproduce a la Gorgona, de $6 \mathrm{cms}$. El basamento se levanta sobre un amplio zócalo cuadrangular ( $8 \mathrm{cms}$. de altura) y está constituido por una gola recta inversa, listel plano, gola recta inversa, y doble caveto inverso (fig. 6a). La moldura superior, muy similar a la del ara anterior, presenta, de abajo a arriba, gola recta, filete, gola recta, listel y cuarto bocel al que se superpone el cimacio con pulvinos de escamas apuntadas imbricadas, balteus en el centro formado por dos anchas fajas lisas y con cabezas de gorgona encerradas en un doble círculo en los extremos. La letra es capital cuadrada y el epígrafe se distribuye en tres renglones que miden: $1.1 .3{ }^{\prime} 95 \mathrm{cms} ; 1.2 .3{ }^{\prime} 2 \mathrm{cms}$. y 1.3. $2^{\prime} 8 \mathrm{cms}$., con unos espacios entre líneas de $2^{\prime} 3 \mathrm{cms}$. entre 1.1 y 1.2 y de $2^{\prime} 3 \mathrm{cms}$. entre 1.2 y 1.3. En cuanto a la paginación del texto, si bien aparentemente es muy regular, en realidad se observa, como en la inscripción anterior, un cierto desplazamiento del texto hacia la izquierda. Los espacios desde la primera y última letra de cada línea hasta el borde del ara son, de izquierda a derecha, 1.1, 3'5-5' 5 cms.; 1.2, 13'5-7'3 cms. y 1.3, 4'5-6'5 cms. Se conserva actualmente en el Museo Arqueológico Municipal de Cartagena. La lectura del texto es la siguiente:

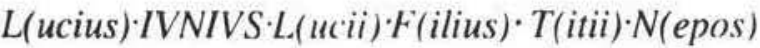

PAETVS

FORTVNAE:SAC(rum) $D($ onum $) \cdot D($ edicavit o Dedit $)$

\section{COMENTARIO}

Sorprende, en primer lugar, la dedicatoria a Gaius Caesar que aparece en dos de las inscripciones, ya que parece lógico restaurar la parte que falta en la inscripción núm. 1 con el praenomen 

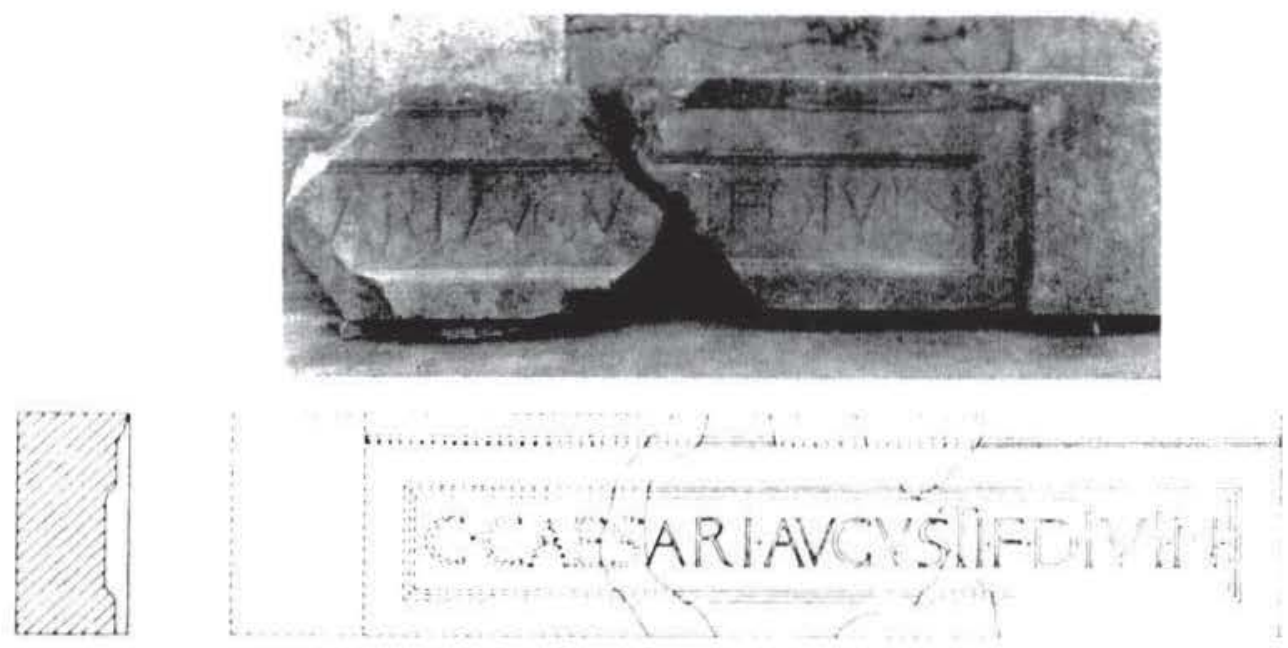

Figs. 4 y 5. Inscripción monumental dedicada a C. Caesar, hallada desplomada sobre uno de los itineray restitución de la inscripcion n." 1.

de Gaius, y que sin duda es una muestra clara de la estrecha vinculación del nieto adoptivo de Augusto con la ciudad que hasta ahora desconocíamos. La reiteración de la dedicatoria nos hace incluso sospechar una intervención directa de este personaje en la financiación del mismo teatro. pero incluso hay que pensar que esta relación con la ciudad va más allá de un simple acto de generosidad o prodigalidad con los nuevos ciudadanos '. En cualquier caso, las nuevas inscripciones demuestran ya de manera definitiva el gran apogeo que desde el punto de vista urbanístico y monumental tiene la ciudad entre los años finales del siglo 1 a.C. y los primeros del siglo I d.C. 6 .

Así, la datación de las inscripciones, al menos de las dos aras que parecen corresponder a un mismo programa, período y taller, dada la gran similitud que existe entre ambas ${ }^{7}$, y muy pro-

'Aún no esta claro el momento de concesión del estatuto colonial a la ciudad y si éste es una promoción desde un estado municipal o de ciudad privilegiada. Tradicionalmente se ha venido aceptando la fecha propuesta por A. Beltrán a partir de la evidencia numismática, (vid. "Las monedas latinas de Carthago Nova". Anale's de la Universidad de Murcia. 1949, 117-186), como una refundación de Cn. Statilio Libo como legado del triunviro Emilio Lépido en el año 42 a. C., aunque realmente las emisiones de Carthago Nova con leyenda Colonia Urbs lulia Nova Carthago no aparecen de forma clara - dejando a un lado la emisión más antigua con cabeza de Palas y estatua femenina - más que a finales del reinado de Augusto o principios del de Tiberio. Por otra parte, la emisión que servia de argumento a Beltrán ha sido extraída de las series de Carthago Nova y tras un riguroso estudio se ha considerado que debe vincularse a otra ceca hispana de ubicación incierta. Vid. Lloréns, M. M.: «La emisión de Cn. Stati. Libo Praef.». Sagumtum. 22, 1989, pp. 319-342.

" Para el análisis de los testimonios que reafirma este período de esplendor de la ciudad portuaria puede verse ahora, Ramallo, S.: La ciudad romana de Carthago Nova, Vol. II: La documentación arqueológica. Univ. de Murcia, 1989.

${ }^{7}$ El mármol utilizado, probablemente del pentélico, es muy puro, de grano muy fino y excelente calidad con abundantes cristales maclados y exfoliación perfecta, y es prácticamente idéntico al utilizado para los grandes capiteles corintios. Análisis petrográficos y observaciones comparativas han sido realizadas por el Dr. R. Arana Castillo, Catedrático de Geología de la Universidad de Murcia, a quien agradecemos 
bablemente la inscripción monumental a juzgar por el desarrollo propuesto para su leyenda, queda claramente indicada por el cursus honorum del joven princeps. Hijo de Agrippa y Julia, nieto por tanto de Augusto, Gaius nace el año 20 a.C., es adoptado por Augusto en el año 17 a.C. y muere en Licia el 21 de febrero del año 4 d.C. ${ }^{8}$. La mención consulis designati restringe la cronología a los años que transcurren entre el 5 a.C., fecha de la designación y el I d.C., año en que Gaius ocupa el consulado (desde el uno de enero) con L. Aemilius Paullus primero y con M.Herennius Picens desde las Kal. Iulii ${ }^{9}$.

La filiación completa que hallamos en la inscripción núm. 1, Augusti.f(ilio).divi.n(epoti), se repite también en otras inscripciones conmemorativas de Mediolanium, Varagronum y Cástulo, donde ostenta ya también los títulos de consul (año 1 d.C.) e imperator (año $2 / 3$ d.C.) ${ }^{10}$, y con la misma titulatura también en Agedincum (en la provincia Lugdunensis) ${ }^{11}$, mientras que en Soriano Polimartium (Bomarzo) aparece aún como consul designatus ${ }^{12} \mathrm{El}$ grupo más numeroso de inscripciones es el que nos lo presenta como consul, junto a los títulos de pontifex y princeps iuventutis, que aparecen en las inscripciones de Sulmo (Solmona), Angulus (Spoltore), Ariminum, Abellinum, Nola y Medellín ${ }^{13}$. Finalmente, inscripciones gemelas a la de Cartagena son las de Augusta Pretoria ${ }^{14}$ y Sagunto, donde se inscribe sobre un pedestal de estatua con base y cornisa ${ }^{15}$. La mayoría de estas inscripciones parecen corresponder a basamentos o pedestales de estatuas ${ }^{16}$ y en muchas ocasiones aparecen asociadas a epígrafes gemelos dedicados a su hermano Lucius $^{17}$. Incluso conocemos también una inscripción colectiva dedicada a Gaius por $\mathrm{Ga}$ llaecia, hallada en Bracara Augusta ${ }^{\text {ix} .}$

el interés por resolver con prontitud las cuestiones que le hemos planteado. Para la comparación del material pétreo puede verse, Alvarez, A. y otros: «Identificacion de materiales lapideos arqueológicos mediante difraccion y fluorescencia de rayos X», Bol. Soc. Esp. de Mineralogía, 8, 1985, 399-406, y especialmente fig. 1 .

${ }^{8}$ Vid. en general, $R E$, s. v. Iulius, col. $424, \mathrm{n}^{\circ} 134$ y también $P I R$, ii, p. $174, \mathrm{n}^{\circ} 141$. Para el cenotafio de Lycia vid. Borchardt, J., en JDAI, 89, 1974, 217 y ss. y Ganzert, J.: Das Kenotaph für Gaius Caesar im Liyra. Inst. Frsch. 35,1984.

${ }^{9}$ Degrassi, A.: I Fasti consolari dell Impero romano dal 30 avanti Cristo al 613 dopo Cristo, Roma, 1952; o también Schillinger-Häfele, W.: Consules. Ausgusti Caesares. Datierung von romischen Inschriften und Münzen. Limesmuseum Aalen, 1986., y también P.I.R., pars IV, 216, pag 165-168.

${ }^{10}$ Respectivamente, CIL, V, 6416, CIL XII, 141 y CIL,II,3267.

" CIL, XIII, 2942.

${ }^{12}$ Respectivamente CIL, XI, 1, 3040 y CIL, XIV, 2910.

${ }^{13}$ Respectivamente, CIL, IX, 3078 y 3343, CIL, XI,1, 366, CIL X, 1115 y 1239 y CIL, II, 607. 14 CIL, V, 6835:

${ }_{14}^{14}$ [c.]caesari.august/i.f.]./[p]rincipi.iuventut/is]./[p]ontifici.cos.desig./d.d.

${ }_{15}$ CIL, II, 3828: c.caesari.augusti.f./pontif.cos.design./ principii.iuventutis. y Beltrán, F.: «Epigrafía latina de Saguntum y su territorio", SIP, 67, Valencia, 1980, n. 11, lám. IV, aquí con interpunciones de triángulos hacia arriba.

${ }^{16}$ Vid. el análisis de todas estas inscripciones dedicadas a Gaius y Lucius Caesar en Hanson, C. y Johnson, F. P.: «On certain portrait inscriptions», $A J A, 50,3,1946$, pp. 388 y ss. especialmente 388-390.

17 Por ejemplo en Soriano Polimartium (Bomarzo, Etruria meridional), CIL, XI,1, 3040 y también ILS, 106, e incluso más claramente, sobre dos basas iguales, en Roma, CIL, VI, ns. 897-898, también en Mediolanum, CIL, V, 6416, las más conocidas inscripciones de Pisa, CIL, VI, 1420-1421 y en la más difundida del arquitrabe del templo de Nimes, CIL, XII, 3156. Vid. también para el comentario e historia 

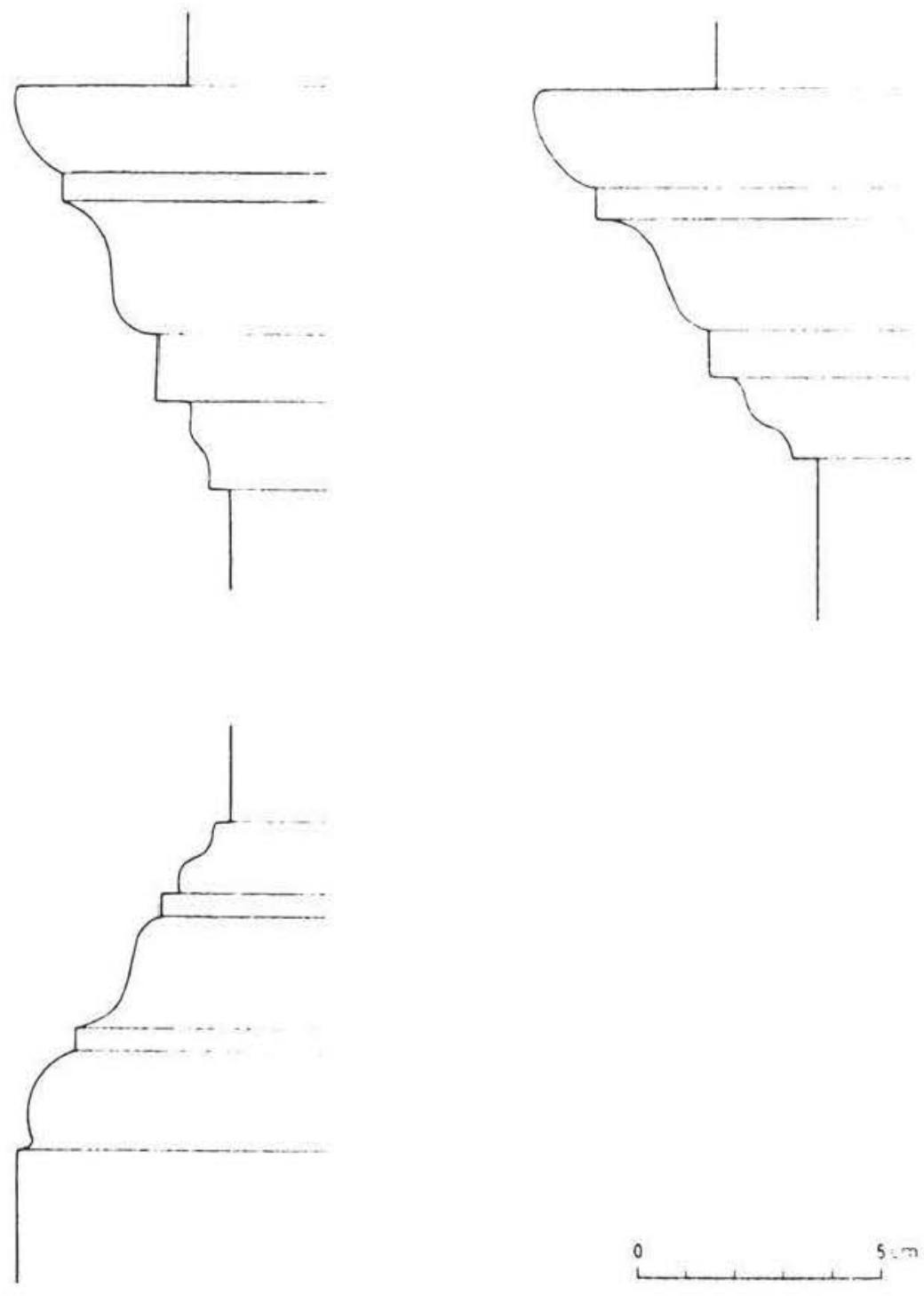

Fig. 6. Perfiles de las molduras de remate de las aras.

Por otra parte, es muy interesante destacar la amplia representación de los dos principes, nombrados ya sus sucesores por Augusto, y en muchas ocasiones estrechamente vinculados a su figura, en las monedas hispánicas fechadas entre los años 6 a.C. y 4 d.C. ${ }^{19}$. Gades presenta sobre un sextercio las cabezas de Gaius y Lucius rodeadas por una corona de laurel

de esta inscripción Balty, J.: Etudes sur la Maison Carrée. Collection Latomus, XLVII, especialmente pp. 150-177, y Amy R. y Gros, P.: La maison carrée de Nimes. CNRS, 1971.

${ }^{18} \mathrm{CIL}$, II, 2422, c.caesari.aug.f./pontif.auguri./ gallaecia.

${ }^{19}$ Para el significado de estas emisiones, Sutherland, C. H. V.: «Aspects of imperialism in Roman Spain», JRS, XXIV, 1934, pp. 31-42 y especialmente p. 35. y también, Etienne, R.: Le culte impérial dans la Peninsule Ibérique d'Auguste a Diocletien, París, 1958, especialmente pp. 397-399. 
como conmemoración de su proclamación como principis iuventutis acompañadas en el anverso con la efigie desnuda de Augusto y leyenda Augustus ${ }^{20}$, que para Villaronga deben coresponder al año 4 a.C. De hacia el año 2 a.C. deben ser los dupondios de Iulia Traducta con el anverso de cabeza desnuda de Augusto y leyenda Perm.Caes.Aug. y en el reverso las efigies de Cayo y Lucius, con leyenda C.L.Caes.Iul.Trad. Esta misma ciudad emite semises con la cabeza desnuda de Gaius y reverso de racimo y la de Lucius con reverso de espiga ${ }^{21}$. En Tarraco, ases posteriores al año 2 a.C. con cabeza de Augusto, pontifex max. y p.p. en el anverso y reverso con las cabezas enfrentadas de Gaius y Lucius con leyenda C.L.Caes.Aug.f./C.V.T. y semises con reverso de Gaius y Lucius de pie apoyados en escudos que copian el denario de Augusto con leyenda C.L.Caesares.Augusti.f.cos. desig princ.iuvent ${ }^{22}$. Por último, en Caesaraugusta sobre las emisiones de dupondios de $C n$. Dom.Ampian y C.Vet.Lancia. las estatuas de Augusto, Gaius y Lucius con sus correspondientes pedestales aparecen con la inscripción Imp.Aug.C.Caesar:L.Caesar:Cos.Des ${ }^{23}$. Todo ello se enmarca en una política bien definida de muchas de estas ciudades hispanas que buscan mediante el nombramiento como patronos de personajes importantes de la vida pública romana muy próximos al emperador -en ocasiones incluso de la propia familia imperial-, la propia promoción política extralocal de sus ciudadanos o de la misma ciudad ${ }^{24}$. Este fenómeno es sobre todo visible en Carthago Nova, donde en un corto espacio de tiempo se nombran sucesivamente a M.Vipsanio Agripa, padre de Gaius y Lucius ${ }^{25}$, probablemente entre el 19 y el 12 a.C., P.Silius Nerva, personaje muy vinculado al propio Agrippa, entre 19 y el 16 a.C. ${ }^{26}$, Ti. Claudius Nero, entre el 29 y el 12 a.C. ${ }^{27}$, y también Iuba II de Mauritania entre los años $1-10$ d.C. ${ }^{28}$. A todos ellos hay que añadir ahora la figura de Gaius como un personaje importante en la vida pública de la ciudad que, paradójicamente, y frente a lo que ocurre con Iuba II, Agrippa y Ti.Claudio Nerón, no ocupa la más alta magistratura ciudadana, la de IIvir quinq. Tampoco, y de momento, no hay testimonio alguno, más allá de las inscripciones objeto de análisis, que pueda relacionarse con un posible patronazgo sobre la ciudad. Sabemos que Gaius es nombrado patrono de Salaria y de Ulia ${ }^{29}$ y ya fuera de la Península Ibérica destacan los patronaz-

\footnotetext{
${ }^{20}$ Villaronga, L.: Numismática antigua de Hispania, Barcelona, 1979, p. 250, n 944.,

21 Villaronga, op. cit., p. 268 y fig. 1013 y ff. 1011 y 1012.

${ }^{22}$ 'Villaronga, op. cit., p. 259, ff. 952-954.; para el denario, BMC, I, 513-538, de la ceca de Lugdunum.

${ }^{23}$ Villaronga, op. cit., fig. 981 ,

${ }^{24}$ Abascal, J. M. y Espinosa, U.: La ciudad hispano-romana. Privilegio y poder. Logroño, 1989, pp. 126-127, con la bibliografía general sobre el tema.

${ }^{25}$ Koch, M.: "M.Agrippa und Neukarthago", Chiron, 9, 1979, 205-214.

${ }^{26}$ CIL, II, 3414, y Alföldy, G., Flamines Provincia Hispania Citerioris, 1975, n. ${ }^{\circ} 7$.

${ }^{27}$ CIL, II, 5930 y Beltrán, A.: «Las inscripciones latinas honorarias de Carthago Nova», RABM, 1949, 523-547.

${ }^{28}$ CIL, II, 3417, y A.Beltrán, op.cit. (n. 27), 523-547.

${ }^{29} \mathrm{CIL}, \mathrm{II}, 1526$, c.caesari/augusti.f./patrono; Hübner sugiere que esła inscripción formaría parte junto a otras cinco de un grupo que incluiría también a Augusto, Agrippa, Postumo, Tiberio y Antonia, vid. para el comentario, Hanson y Johnsonm: op. cit., p. 390. También CIL, II, 5093, [c.ca]esari.[divi]/[au]gusti.f.[pa]/[t]rono./coloni. Una nueva inscripción gemela de la anterior aunque sobre un soporte diferente dedicada en este caso a Lucio César, procedente asimismo de Montemayor/Ulia ha sido publicada recientemente por Lacont, P.J., Portillo, R. y Stylow, A.: Nuevas inscripciones latinas de Córdoba y su provincia, Faventia, 8,1, 1986, pp. 88-89.
} 

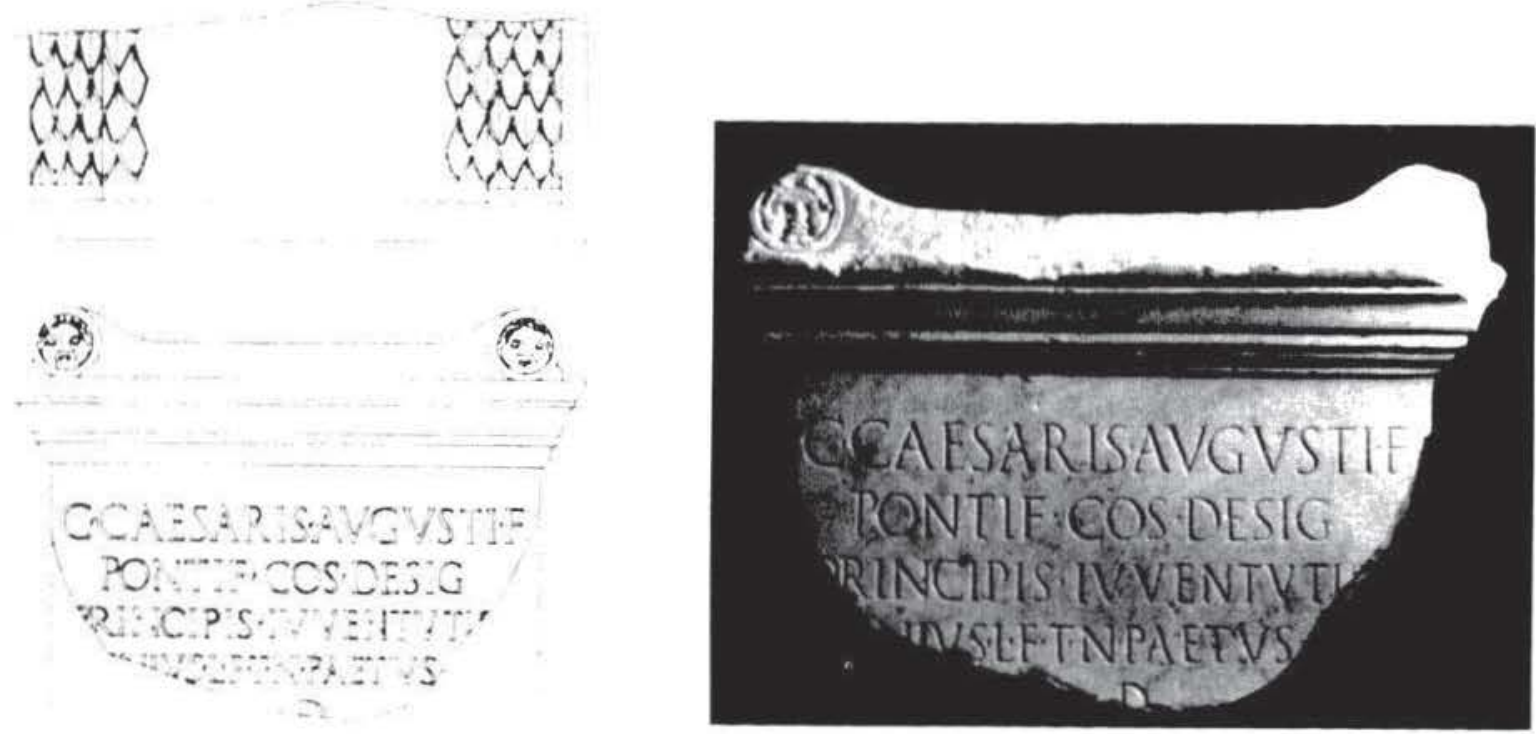

Figs. 7 y 8 . Ara de C. Caesar hallada en la Taberna 1-3.

gos sobre Nemausus ${ }^{30}$, donde precisamente y al igual que en Carthago Nova, años antes había sido nombrado patrono el propio Agrippa ${ }^{31}$, así como los de Rusellae y Pisa ${ }^{32}$. En nuestro caso, no sabemos hasta qué punto se puede hablar de un compromiso del propio Agrippa con la ciudad en su visita del año 19/18 a.C. que se habría plasmado en el inicio de este edificio, terminado tras su muerte por su hijo Gaius.

Desde el punto de vista sintáctico destaca en la inscripción el uso del genitivo en la dedicatoria en lugar del dativo propio de estas dedicatorias conmemorativas. Hay que descartar en primer lugar que se trate de un error del copista ya que todo el cursus aparece en clara concordancia con el nombre. En cualquier caso, este mismo fenómeno se reproduce sobre sendas inscripciones monumentales y conmemorativas de Reims y Trier, consideradas por los editores posteriores a la muerte de los dos hermanos ${ }^{33}$. En este sentido, el genitivo de nuestra inscripción podría hacernos pensar en la existencia de un sustantivo, bien sobrentendido, elíptico — aramo bien sobre alguna parte del monumento desaparecido que podría venir a indicar alguna cualidad o virtud del joven príncipe. Es difícil restituir aquí el término memoria, que implicaría ya

\footnotetext{
${ }^{10}$ CIL. XII, 3155.

"Amy y Gros, op. cit., p. 194.

2 AE. 1980, n. 449. /c(aio).calesari./aug(usti).f(ilio).../.../patron/o.../.
}

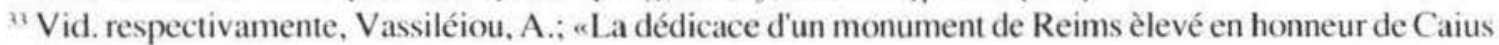
et Lucius Caesar», ZPE, 47, 1982, pp. 119 ss., y también, Heinen, H.: Trier, Augustadt der Treverer, Mainz, 1984, p. 231. Este último autor restituye Memoriae para ambas inscripciones, mientras que Vassiléiou sugiere la posible restitución de manibus, poniéndola en relación con CIL. XI. 1421, 31-33. En esta misma dirección se ha manifestado recientemente Gros, al proponer Dis Manibus, Vid.4es autels des Caesares et leur signification dans l'espace urbain des villes julio-claudiennes, In: $L$ 'Espace sacrificiel. pp.181-182. 
una dedicación post mortem, que si bien estaría acorde con el título de princeps iuventutis ${ }^{34}$, contrastaría con el de consul designatus título que es sustituido a partir del año uno por el de cónsul. Mas plausible en este caso, y si queremos buscar un posible atributo que justifique el genitivo sería pensar en términos como numen o genio ${ }^{35}$, en cuanto divinidades menores de carácter protector, que podrían también relacionarse con el carácter profiláctico, benefactor y de inmortalidad de las gorgonas que aparecen sobre los extremos de los pulvini de las dos aras ${ }^{36}$. También sería factible sobrentender un dativo (in honorem) C. Caesaris... al modo de la inscripción del teatro italicense dedicada por L. Blattius y $C$. ¿Fabius? ${ }^{37}$. Por otra parte, no existe argumento alguno para afirmar la existencia de una escultura de principe que hubiera estado en relación con el ara, aunque, en cualquier caso, destaca el aspecto descuidado de la parte superior de esta, entre los pulvinos, de superficie rugosa y sin muestras de posible focus, lo que indicaría la existencia de un elemento metálico, seguramente de bronce, que se ajustaría en los resaltes escalonados del frontal del ara. Otra posibilidad, en cambio, nos sugiere el Dr. M. Mayer de que se trate de un genitivo de posesión y consecuentemente haya que sobrentender la expresión ex iussu (que vendría a significar "por mandato de») fórmula que hallamos reproducida en otras inscripciones de características similares ${ }^{38}$ y que justificaría la dedicatoria monumental de la colonia al propio Gaius quien en su condición de patrono de la ciudad habría regalado a sus "conciudadanos» este magnifico edificio, o al menos una parte, igual que años antes su padre había hecho con los ciudadanos de Mérida ${ }^{39}$.

En cualquier caso, tipológicamente, las aras de Cartagena entroncan con una amplia serie de altares y monumentos funerarios en forma de altar frecuentemente decorados con guirnaldas y roleos vegetales, que en algunas ocasiones muestran también la caput Medusae sobre los extremos de

${ }^{34}$ Vid. a este respecto, Amy y Gros, op. cit., 189-194, quienes destacan el carácter sacralizante de tal mención, utilizada sobre todo tras la muerte de los dos principes, «con el fin de sugerir su ascension al mundo de los dioses» en una especie de sincretismo con la figura de los Dioscuros (p.191).

${ }^{35}$ Conocemos varias inscripciones dedicadas numini Augusti, vid. Alföldy, G.: Die römischen Inschriften von Tarraco, Berlín, 1975, $\mathrm{n} .^{\circ} 48$, precisamente inscrita sobre un ara hallada en 1919 en el teatro de Tarragona, posiblemente de época augustea.

${ }^{36}$ Vid. ahora síntesis sobre el carácter benefactor y cualidades de este mítico animal en A. M.Vázquez y J.del Hoyo, La Gorgona y su triple poder mágico.(Aproximación a la magia, la brujería y la superstición), Espacio, Tiempo y Forma, Serie II, 3, UNED, 1990, 117-182, y sobre todo para los distintos tipos de representación en LIMC., vol. IV, ss.vv. Gorgo, Gorgones, pp. 285-362 y sobre todo s.v. Gorgones romanae, pp. 345-362, con bibliografía anterior y comentario.

${ }^{37}$ Canto, A. M.: Notas sobre los pontificados coloniales y el origen del culto imperial en la Bética. $\mathrm{La}$ Religión Romana en Hispania, Madrid, 1981, pp. 143-153.

${ }_{38}$ Vid. así por ejemplo, Dessau, ILS, 8633, Ti.Claud.Caes IV.L.Vitellio III.cos.p.ex.ad Artic.ius.aed.XXX. o mejor, AE, 1978, n. 863, sobre un altar decorado con una corona de hojas y dos tyrsos que flanquean la inscripción ex iusso iovi(s)/Zabazi(i)/ara positalLibero patr(i)/ cural m(arci) Oppin(i) Vital(is). También en Minturno (AE.,1982, n.149,) sobre una inscripción grabada poco después del año 40 a.C. dedicada al deivo iulio/iussu populi romanile lege Rufrena. La repetición de la fórmula en la epigrafía del siglo Iv (c.355-360) sobre una inscripción de Asia Menor, con leyenda [iuss] u d(ominorum) n(ostrorum) Co[nstantii triumfa[tori]s Aug(ustorum) et I/uliani nob(ilissimi) Caes(aris)] / murus aedi[ficatus est] /Hirenopolit[anorum civitati] / Aur(elio Ious[to] com [(ite) et praeside c(uram a(gente)], (Vid. AE, 1974, n. 644.

${ }^{39}$ Para el caso de Mérida, vid. Álvarez Sáenz de Buruaga, J, Observaciones sobre el teatro romano de Mérida, El teatro en la Hispania romana, Badajoz, 1982, 303-316. 

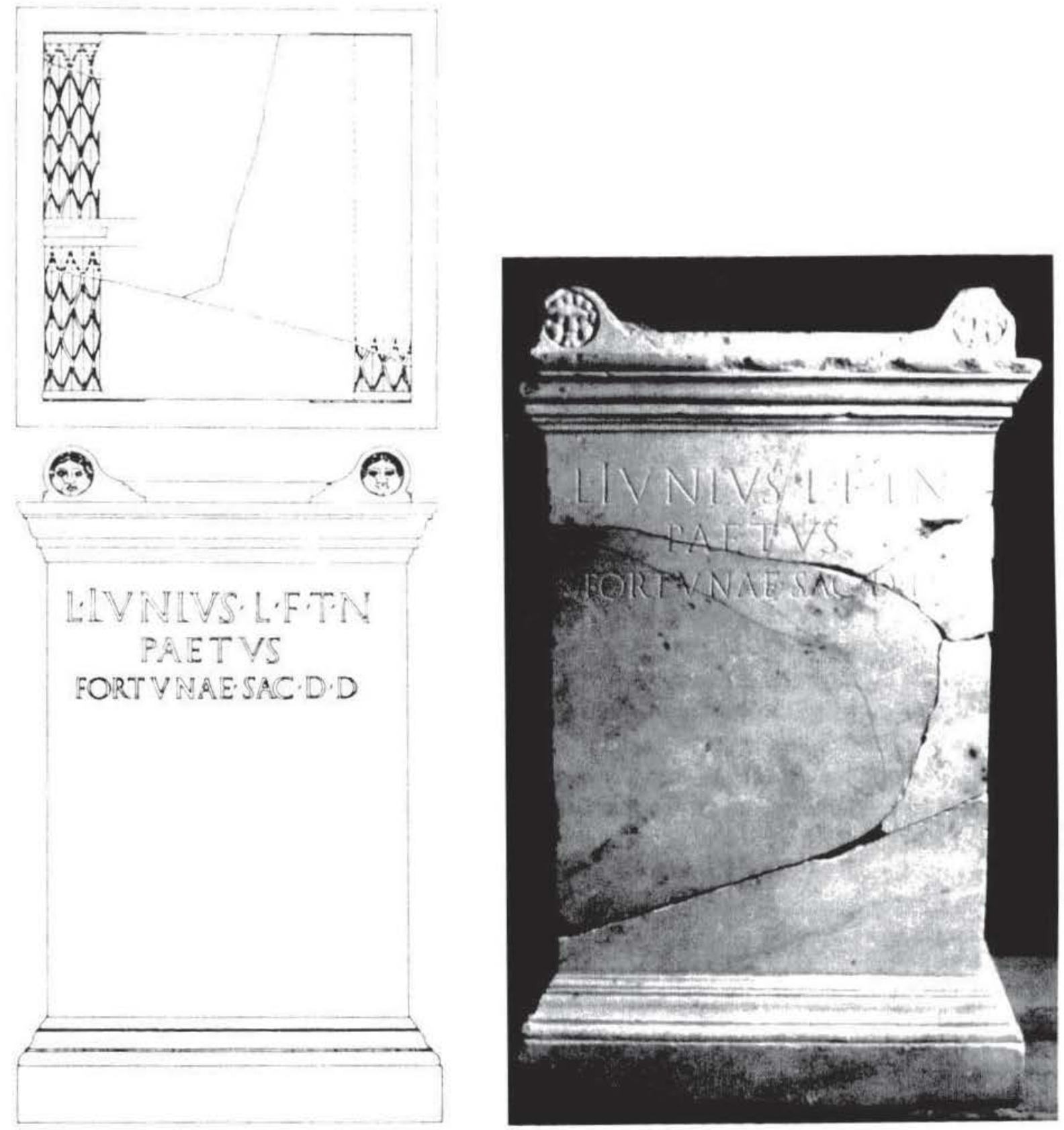

Figs. 9 y 10. Ara dedicada a Fortuna hallada en la taberna 1-3.

sus pulvinos, -ampliamente difundidos en la Península Ibérica desde época flavia si no antes-y los inicios del siglo II d.C. ${ }^{40}$. Así vemos cabecitas de Gorgona en el ara o pedestal de M. Antonius Syriacus de Medinasidonia, formando parte de una rica decoración a base de pilastras con capiteles

4t" Vid. ahora, Beltrán, J.: «Frisos de roleos acantiformes en los monumentos epigráficos de la Bética”. Bactica VIII. 1988. 163-193 y del mismo autor, «Mausoleos romanos en forma de altar del Sur de la Península Ibérica”, $A E$ spA $4.63,1990,183-226$. 
corintios en las esquinas, guirnalda y un frondoso friso acantiforme que encuadra el campo epigráfico. Cronológicamente, el ejemplar ha sido fechado desde época de Claudio hasta los antoninos ${ }^{41}$. Un ara de características similares, aunque de carácter funerario, se localiza en el Museo Nazionale Romano procedente del monumento sepulcral de la gens Ciartia, sobre la vía Ostiense, con cabezas de Amón en los ángulos de cuyos cuernos cuelga un rico festón de flores y frutos y cabeza de gorgona en las acróteras del cimacio, fechado en época flavia ${ }^{42}$. Dentro de esta misma serie hay que situar también el ara de C.Lucretius C.l. Optatus procedente de Collatia, depositada en el Museo Nazionale Romano ${ }^{43}$ y de notable similitud con los ejemplares de Cartagena.

En cuanto a los monumentos funerarios en forma de altar con Gorgoneia, sin duda la serie más conocida aunque su tipología se aleja notablemente de las aras cartageneras nos la proporcionan los monumentos de Barcelona, fechados según Balil entre fines del siglo I d.C. y el primer tercio del siglo III d.C., ejemplares que representarían para este autor una excelente muestra del quehacer cotidiano de los talleres barcinonenses ${ }^{44}$. El máximo desarrollo del tipo lo hallamos sin embargo en el pulvino de un mausoleo de Neumagen en combinación con una compleja representación figurada de los Trabajos de Hércules ${ }^{45}$. También en el Museo de Worms se conserva un altar coronado por una moldura con sendas cabezas femeninas a los la$\operatorname{dos}^{46}$. Se observa de cualquier forma una estrecha relación de las aras de Cartagena con ejemplares de la Península Itálica, si bien en nuestro caso, las aras de Carthago Nova presentan una cronología anterior ( 5 a.C.-1 d.C.) a la de los monumentos citados y bien pudieron formar parte de las series de modelos que inspiraron estas aras de decoración más exuberante y más rica simbología de cronología posterior.

El tema de las hojas imbricadas con nervadura central reproducido sobre los pulvinos ${ }^{47}$, que se populariza como motivo ornamental a partir del siglo I a.C., es frecuente en monumentos funerarios en forma de altar de Italia, Galia y Germania y se localiza asimismo, ya en la Península Ibérica, sobre un ara de Beira litoral ${ }^{48}$, en Barcelona ${ }^{49}$, en la conocida serie de pulvinos con cabezas de Gorgona, así como en una amplia serie de pulvinos de monumentos funerarios béti$\cos ^{50}$. A partir del siglo II el tema se populariza como motivo decorativo en las cubiertas de sarcófagos áticos y del Mediterráneo Oriental ${ }^{51}$.

${ }^{41}$ Beltrán, op. cit. (n. 40),168-173, con análisis del tema de la Gorgona en conexión con roleos vegetales y acantiformes y también Gamer, G.: «Formen römischer Altäre auf der Hispanischen Halbinsel», Madrider Beiträge, 12, 1989, p. 217, fig. 103 b.

${ }^{42}$ Candida, B.: Altari e cippi nel Museo Nazionale Romano, Roma, 1979, n. ${ }^{\circ}$, pp. 23-25, tav. VII y también, W. Altmann, Die Römischen Grabaltäre der Kaiserzeit. Berlín, 1905, n. ${ }^{\circ}$ 54, p. 89, fig.74.

${ }^{43}$ Quilici, L.: Collatia, Forma Italiae, I, 10, 1974, pp. 100-101, fig. 134.

44 Balil, A.: Los Gorgoneia de Barcino, Faventia, 1, 1, 1979, pp. 63-70 y también ahora, Gamer, op. cit., pp. 2128 y láms. 137-139.

${ }^{45}$ Schindler, R.: Führer durch das Landesmuseum Trier, Trier, 1980, p. 103, ff. 330-331.

${ }^{46}$ Vid. Esperandieu, VIII, 1922, pp. 115-116, n. ${ }^{\circ} 6.062$, con inscripción recogida también en CIL, XIII, 6265.

${ }^{47}$ Vid. para el origen de este tema como motivo decorativo, Ovadiah, A.: Geometric and Floral Patterns in Ancient Mosaics, Roma, 1980, pp. 154-156.

48 Gamer, op.cit., p. 208, lám. 142 d.

${ }^{49}$ Gamer, op. cit., p. 189, lám. 137a, n. ${ }^{\circ} 44$.

so Beltrán, J., op. cit., (n. 39).

51 G. Koch y H. Sichtermann, Römische Sarkophage, München 1982, passim. 
De cualquier forma un excelente punto de relación dentro de la propia Cartagena nos proporciona la Ilamada ara de la Salud hallada en el siglo XVI en el monte Sacro. Los problemas que plantea la citada ara son múltiples y afectan desde la determinación de su ubicación original en la topografía de la ciudad, hasta su cronología, pasando por el más importante de su correcta interpretación y significado. Presenta decoración figurada por sus cuatro caras con distintos temas alegóricos: un personaje velado que levanta en su mano izquierda una rama de olivo; dos cornucopias cruzadas llenas de espigas y frutos con una pátera bajo ellas; timón de nave en otro de sus lados, $y$ finalmente un tronco de olivo con una serpiente enroscada. Se podría relacionar la figura velada con la concesión a Augusto del título de pontifex maximus en el año 12 a.C. y en este caso, sería un ejemplo más de devoción de la ciudad al propio emperador ${ }^{52}$. Para Beltrán ${ }^{53}$ los relieves que adornan las caras del ara simbolizan la Paz y los beneficios que de ella se obtienen aunque también en sus tipos hay una alusión clara a Salus y Aesculapio a través de la serpiente y la rama de olivo. Este mismo autor pone en relación la representación del monumento con la moneda de M. Postumio Albino y L. Porcio Capito con sacerdote de pie sosteniendo en sus manos símpulo y ramo de olivo y fecha consecuentemente ambos en el año 2 d.C. Tipológicamente el cimacio bajo del ara del monte Sacro con los extremos de sus pulvinos terminados en pequeñas rosetas, muestra cierta similitud con las del teatro y aunque las molduras de pedestal y remate son ligeramente distintas, no se puede desechar una cronología próxima entre ambos ejemplares. En cualquier caso, no hay que descartar del todo una interpretación dentro de un contexto funerario y privado que invalidaría en gran parte todo lo escrito hasta el momento ${ }^{54}$. No sucede lo mismo con otra ara votiva de Cartagena que C.Valerius Felix dedica a la Victoria Augusta que se podría ubicar en los últimos años del siglo I a.C. ${ }^{55}$ y que entraría dentro de esta serie de honores hacia el emperador y su círculo más inmediato.

En cuanto al dedicante de las inscripciones, L. Iunius L.f.T.n.Paetus, pertenece a una de las familias de más amplio raigambre en la sociedad romana, algunos de cuyos miembros ocuparon altos cargos en la Hispania de época republicana ${ }^{56}$. Ya en época imperial, un L.Iunius Cae-

52 Ramallo, op.cit., p. 94.

${ }^{53}$ Beltrán, A.: «El ara romana del Museo de Barcelona y su relación con el culto de la salud y Esculapio en Carthago Nova», Ampurias, IX-X, 1947, 213-223. Para la descripción y comentario, también Gamer, op. cit., p. 94, 247 y láms. 130 a. b.

${ }^{54} \mathrm{Para}$ Gamer, op. cit., el análisis estilístico conduciría a un momento avanzado del siglo I d.C. lo que invalidaría la interpretación de Beltrán y la vinculación indirecta del monumento a acontecimientos de la vida del emperador.

${ }^{55}$ CIL, II, 3410 y también, C. M." del Rivero, El lapidario del Museo Arqueológico Nacional. Madrid, 1933, n. ${ }^{\circ}$. La dedicatoria es en parte similar a una de Tarraco dedicada a la misma Victoriae Augustae por la colonia Triumphalis Tarraco que alude probablemente a la conquista de Augusto de las tierras del noroeste llevadas a cabo entre el 26 y el 19 a. C., período en el que habría que ubicar la inscripción, vid. G. Alföldy, op. cit., n. ${ }^{\circ} 58$, lám. XIII, 2.

56 Vid. por ejemplo M. I. Silanus que fue propraetor en Hispania entre los años 210-206 a. C., o también un $M$. I. Silanus praetor en los años 113 o 112 a. C. Vid. RE, s. v. Iunius y también, T. R. S. Broughton, The Magistrates of the Roman Republic, vols,. I y II, New York, 1952 y vol. III, suppl. Atlanta, 1986. Por otra parte el gentilicio es muy frecuente en Hispania donde se localiza sobre 123 inscripciones, (CIL, II, index nomina virorum et mulierum, p. 1065) pero también en Italia (53), Gallia Belgica , Gallia Narbonensis, Dalmacia, Panonia, y en general está presente en todas las provincias del Imperio, vid. A. Mocsy, et. alii, Nomenclator provinciarum Europae Latinarum et Galliae Cisalpinae, Budapest, 1983. y 
sennio Pactus fue cónsul junto a P.Petromio Turpiliano en el año $61^{57}$ y otro Iunius Paetus fue cónsul sufecto, junto a P.Tullius Varro, en el año $127^{5 x}$. En Carthago Nov'a, esta gens no se había considerado hasta ahora como una de las grandes familias de la ciudad ${ }^{51}$. Un L. Iunius, IIvir quinq. firma junto a $L$. Acilius una serie de semises y quadrantes que Beltrán fecha en el año 37 a.C. ${ }^{60}$, con leyendas y tipos en los semises de L.Acilius.IIvir.quinq.Augur junto a la pátera. el praefericulo y lituo y en el reverso, L.Iunius. IIvir: quinq. Augur, y el águila sobre rayo con el lituo delante; los quadrantes con L.Acilius, pátera y lituo y L.Iunius, praeferículo. No podemos precisar del todo la relación del llvir quinq. con nuestro personaje aunque a juzgar por la cronología de la emisión monetal, habría que interpretarlo como su padre, de nombre asimismo L.Iunius, sin embargo, también es posible pensar que el Ilvir de las monedas sea el mismo dedicante de las inscripciones, con lo cual habría que modificar la cronología de la emisión monetal y habría que buscar un nuevo significado al Aug que aparece junto a la magistratura monetal y que Beltrán relacionó con el título de Augur obtenido por Octavio en el año 37 a.C. En este caso podría tratarse de un cargo ostentado por el propio lunius Paetus al igual que también lo fueron en la ciudad M.Cornelius Marcellus y un Maecius Vetus ${ }^{61}$, del cual desconocemos el

H. Solin-O. Salomies, Repertorium nominum gentilium et cognomina Latinorum, Hildesheim, 1988. En la Bética, los lunii ocupan magistraturas a lo largo de toda la República y personajes con este gentilicio ostentaron cargos locales en muchas de sus ciudades, vid. Castillo, C.: Prosopografía Baetica. Universidad de Navarra, Pamplona, 1965, pp. 402-404. Concretamente, en Cástulo, ciudad estrechamente vinculada con Carthago Nova por su orientación económica eminentemente minera, los Iunii junto a los Conerlii y los Valerii constituían la aristocracia local en el siglo I y su importancia arranca desde los primeros años de la conquista romana, Vid. Blázquez, J. M.: «Cástulo a través de sus inscripciones latinas», Epigraphie Hispanique, Problèmes de méthode et d'édition, París, 1984, pp. 301-314, especialmente p. 306.

${ }^{57} \mathrm{AE}, 1973, \mathrm{n} .141$ y 142, tabulae ceratae del agro di Murecina; se trata seguramente de Puteoli.

${ }^{5 *}$ AE, 1977, inscripcion procedente de Dacia, n." 701, este lunius Paetus seria sobrino de D. Iunius $L$. Caesennius Paetus, cónsul del 79. No sabemos hasta qué punto existe una relación directa de todos estos personajes con nuestro lunius Paetus, tan sólo queremos destacar la estrecha relación que, en otros aspectos (sobre todo comerciales) existe durante la época tardo-republicana y el siglo I d. C. entre la ciudad hispana y los principales puertos de Italia central y meridional. Vid. también PIR, IV, 3, n. 790.

${ }^{59}$ Vid. para estas gentes cuyos miembros (ingenui, libertos y esclavos) aparecen ampliamente representados en la epigrafía, la numismática y en cartelas de lingotes tardo-republicanos y de inicios del Imperio, Koch, M.: "Las 'grandes familias' en la epigrafía de Carthiago Nova», Actas del ler Congreso Peninsular de H. ${ }^{a}$ Antigua, Santiago, 1988, 403-407. También es interesante para el estudio de las familias que controlaban las explotaciones mineras cuyos gentilicios se repiten en los duoviri quinquenales de las emisiones monetales, Domergue, C.: «L'exploitation des mines d'argent de Carthago Nova: son impact sur la structure sociale de la cité et sur les dépenses locales a la fin de la république et au début du Haut Empire», in.: Ph. Leveau (éd.), L'origine des richesses dépensées dans la ville antique. Aix, 1985, 197-217.

${ }^{6}$ Beltrán, A.: «Las monedas latinas de Cartagena», AUM, curso, 1948-1949 pp. 29-30 (de la l.“ tirada aparte) y Grant, M.: From Imperium to Auctoritas, Cambridge, 1978 (1.a ed. 1946), pp. 215-217.

${ }^{61}$ Para M. Cornelius Marcellus, augur, CIL, II, 3426, para Maecius, vid. Koch, M.: «Neue römische Inschriften aus Carthago Nova", MDAI (M), 17, 1976, 292-294. Un C. Maecius Celer conocemos en una inscripción de Ilici, CIL, II, 3555, lo que hizo a Grant, op. cit., pp. 213-214, atribuir las emisiones monetales de $C$. Maecius a esta ciudad. Ver para su reubicación en las series de Carthago Nova, Llorens, M. M.::La Ceca de llici, Valencia, 1987.

Para los augures en la Península Ibérica, vid. CIL, II, index y también para la problemática Galsterer, H.: Untersuchungen zum römischen städtenwesen auf der Iherische Halbinsel, Berlín, 1971, pp. 59-61, especialmente notas $87-88$. 
praenomen. pero emparentado con toda probabilidad con el C. Maecius que como quinquennalis acuña junto a L.Acilius, quinquenal en las emisiones de nuestro personaje. En este sentido, se podría pensar en una restitución con la abreviatura AVG en la inscripción de Gaius y Caesar tras la filiación del personaje, lo que coincidiría con el cursus reflejado en las monedas. Sin embargo, el carácter de aras gemelas nos induce mejor a restituir la abreviatura SAC (rum), tras el cursus del princeps en concordancia con la dedicatoria de la inscripción n. ${ }^{\circ} 3$, completa, donde paradójicamente no se presenta el cargo sacerdotal. Por el contrario, el magistrado monetal, $L$. Iunius es para Curchin, quizás, posterior al año 5 d.C. ${ }^{62}$.

El cognomen Paetus, atestiguado ya en época republicana ${ }^{6.3}$ y durante el siglo I d.C. ${ }^{64}$ es relativamente raro en la Península y lo conocemos en Cartagena por un fragmento de inscripción sobre micrita gris actualmente incrustada sobre los muros de cimentación de la Catedral Vieja, muy próximo a donde aparecieron las otras inscripciones, que conserva este apelativo ${ }^{6.5}$. El mismo cognomen lo hallamos también sobre una inscripción funeraria de Huescar, en la provincia de Granada ${ }^{66}$, y en su forma femenina sobre una inscripción de Martos (Jaén) ${ }^{67}$. De Coimbra es un M.Preccius Paetus publicado por Encarnaçao ${ }^{68}$.

Este orgullo y raigambre por los miembros de la gens, que mencionábamos más arriba, se manifiesta en la filiación completa expresada por el personaje en la inscripción, hijo de Lucius, nieto de Titus ${ }^{69}$. Curiosamente se reproduce aquí la fórmula empleada en la inscripción monumental de G. Caesar donde también se especifica la filiación con Augusto y la descendencia con el divino Cesar, fenómeno que se repite en las grandes inscripciones conmemorativas de Cartagena. Así luba II de Mauritania remonta su filiación al rey Masinissa (abnepoti), $y$ otros personajes pertenecientes a familias de gran renombre: L.Aemilius, hijo de Marco, nieto de Marco o L.Sulpicius, hijo de Quinto, nieto de Quinto ${ }^{70}$.

Respecto a la dedicatoria a Fortuna de la inscripción n. ${ }^{\circ}$, realizada por el mismo L.Iunius Paetus, se puede incluir, en primer lugar dentro de una amplia serie de testimonios epigráficos y numismáticos cartageneros donde se rememoran personificaciones de divinidades abstractas relacionadas en muchos casos con la figura del emperador o la familia imperial. Hemos men-

${ }^{62}$ Curchin, L. A.: The Local Magistrates of Roman Spain. Toronto, 1990, p.194, n. 569.

${ }^{6.3}$ Vid. Solin, H.: «Die innere Chronologie des Römischen Cognomens». L'onomastique latine. Colloques du CNRS, n. ${ }^{\circ}$ 564, París, 1977, p. 127.

${ }^{4}$ H. G. Plaum, «La Gaule et l'empire romain». Études èpigraphiques. Scripta varia II, pp. 170, $176,177$.

${ }^{65} \mathrm{CIL}, \mathrm{II}, 3515$, [-IALLVS/-III-IPAETVS/-I.

${ }^{66}$ Seguramente un L. Manlio Paetus, Vid. ahora Pastor, M. y Mendoza, A.: Inscripciones latinas de la provincia de Granada, Granada, 1987, pp. 159-160.

${ }^{67} \mathrm{CIL}, \mathrm{II}, 1707$. Fuera de la Península es también relativamente raro y tan sólo hallamos algunos ejemplos en Italia, Gallia Narbonensis, Dalmacia, Panonia, Aquitania y Moesia Superior, vid. Mocsy, op. cit., y también, Kajanto, I.: The Latin Cognomina, Helsinki, 1965, p. 239, Paetus/ta.

${ }^{68} \mathrm{AE}, 1984$, n. 464 y J. d'Encarnaçao, Inscriçôes romanas do conventus Pacensis. Subsídios para o estudo da romanizaçao. 1.2. Coimbra, Inst. de Arqueologia da Faculdade de Letras, 1984, n. 595.

${ }_{69} T$ (itus) Iunius $L$ (ucii) f(ilius) fue tribuno de la plebe antes del 90 a.C. aunque de momento no podemos establecer vinculación alguna con nuestro personaje. Vid. Broughton, op . cit. II, p.470. Sabemos de la masiva emigración que la Guerra Social provocó en Italia y concretamente en Roma donde un grupo importante de personajes públicos del bando sertoriano debió exilarse tras la victoria de Sila (la costa mediterránea y concretamente Carthago Nova pudieron suponer importantes puntos de inmigración).

${ }^{70}$ Respectivamente, CIL, II, 3417,3423 y 3504. 
cionado más arriba, la inscripción de la Victoria Augusta, que Etienne, recogiendo la datación propuesta por Hübner, fechó sin fundamento dentro del siglo II ${ }^{71}$; a ella habría que añadir las múltiples alusiones a Salus Augusta de las monedas, que en este caso podríamos hacer extensiva a la vecina Ilici, e incluso el ara del monte Sacro donde precisamente sobre dos de sus caras se reproducen dos de los atributos más característicos de la Fortuna, el cuerno de la abundancia y el timón. Según la tradición, el culto a Fortuna habría sido introducido en Roma por el rey Servio Tulio, difundiéndose, con mayor o menor intensidad, según períodos durante la época republicana, en que se le erigen numerosos templos en la propia Urbs y en otras ciudades centro-itálicas, para conocer un nuevo apogeo en época tiberiana ${ }^{72}$. En parte asimilada a la Tyche griega, Fortuna romana adopta muy pronto una serie de epítetos y comienza a vincularse con otras abstracciones divinizadas (Fides, Spes, Faustitas, Salus, etc.) ${ }^{73}$ que diversifican su significado aunque siempre en el marco de una divinidad protectora y, al menos en un principio, benefactora (aunque también a veces mala o adversa) que se hace extensiva a todo el pueblo romano (Fortuna Publica Populi Romani), a una ciudad (tyche Ayaze-Fortuna-Tutela), a una determinada clase social (Fortuna Equestre), se asocia al propio emperador (Fortuna Augusta o Fortuna Redux ${ }^{74}$ que garantiza el feliz retorno del emperador) o a los mismos particulares (Fortuna privata). El carácter de la ciudad y su emplazamiento, puerto insalubre, justifican todas estas advocaciones, en una ciudad donde la principal actividad económica estaba estrechamente vinculada con el comercio - especialmente marítimo-. No por capricho Estrabón $(I I I, 4,6)$ señala Carthago Nova como el principal emporio para las mercancías que llegando del interior han de ser cambiadas por las que vienen del mar y estas por las que proceden de tierra adentro. En este contexto, encuentra clara justificación la alusión a la Fortuna que garantiza el éxito de los negocios y la prosperidad de la ciudad, al tiempo que proteje a sus ciudadanos, el primero de los cuales, en su calidad de patrono, sería, sin duda el propio Gaius Caesar.

Consecuentemente la erección de altares, pedestales y estatuas o la simple dedicatoria de epígrafes a la Fortuna, en sus distintas advocaciones, fue frecuente en todas las regiones y provincias del Imperio. Tan sólo en Hispania conocemos dedicaciones a Fortuna ${ }^{75}$, Fortuna Augusta ${ }^{76}$, Fortuna Redux ${ }^{77}$ y Fortuna Balnearis ${ }^{78}$, entre otras y la erección de aras fue frecuente ${ }^{79}$.

Pero es sobre todo muy interesante destacar la aparición de este nuevo testimonio de advocación a Fortuna en una ciudad donde los cultos a Aesculapio y Salus estuvieron tan extendi-

${ }^{7}$ Etienne, op. cit., p. 325.

72 J.A. Hild, Daremberg-Saglio, s.v. Fortuna, pp. 1264-1277, y más recientemente, Champeaux, J.: Le culte de la Fortuna à Rome et dans l'Empire romain, I. 1982.

${ }^{73}$ Kajanto, I.: Fortuna, ANRW, 17,1, Berlín, 1981, 510-516.

${ }^{74}$ Precisamente a Fortuna Redux se dedican algunas emisiones monetales de época augustea de $\mathrm{Co}$ lonia Patricia, F. Chaves, La Córdoba hispano-romana y sus monedas. Sevilla, 1977.

${ }^{75}$ CIL, II, 331, 337, 467, 1637, 2103, 2127, 2191, 2407, 2558, 5262, 5664.

${ }^{76}$ Etienne, op. cit., p. 332, y CIL, II, 13, 1278, 1934. AE, 1983, 601, de Canales de la Sierra (Rioja).

${ }^{77}$ CIL, II, 2773.

${ }^{78} \mathrm{CIL}, \mathrm{II}, 2701,2763$, respectivamente de S.Juan de Tremanes (Asturias), (fortunae /balnearil t.pompeius. pelregrinianus/pro salute/sua e suorum/dedicavit) y Duratón. Vid. también, Diez de Velasco, F.P.: "Balnearios y dioses de las aguas termales en Galicia romana», $A E s p A, 58,1985$, pp. 69-98, y especialmente, 75-76.

79 Vid. G.Gamer, op.cit. altares procedentes de Beira litoral (Portugal), Monasterio de Rodilla (Burgos), Boñar (Lérida), Herramélluri (Logrono) y Uxama (Soria). 
dos; incluso se puede ver una cierta relación entre los tipos iconográficos del ara del monte Sacro, varias veces mencionada, con la figura velada que porta la rama de olivo y la serpiente enroscada que han sido relacionadas con los cultos de Salus y Aesculapio y el timón y las cornucopias, como atributos característicos de Fortuna. Esta misma asociación se plasma también sobre una inscripción de Bonna en cuyo comienzo se lee Fortuna Salutaris, Aesculapio et Hygiae $^{80}$. En este sentido, González Blanco ha insistido recientemente sobre la existencia de un culto a Fortuna Balnearis en el importante complejo de baños salutíferos de Los Baños en la moderna población de Fortuna, topónimo éste que sin duda hay que remontar a época romana y vincular con la divinidad homónima. La relación entre ambas poblaciones es evidente e incluso se ha llegado a plantear la posible existencia de una vía que comunicara directamente ambas poblaciones. En cualquier caso los epígrafes pintados sobre la Cueva Negra, muy próxima a los Baños, han confirmado, como se ha demostrado recientemente, esa vinculación ${ }^{81}$ con la ciudad portuaria, relación que se aprecia también en el importante complejo de baños salutíferos de Archena, cuya restauración corresponde en parte al duovir L. Heius Labeo, personaje perteneciente a una gens bien atestiguada en los principales puertos mediterráneos dedicada fundamentalmente al comercio marítimo ${ }^{82}$. La inclusión de ambos espacios dentro del territorio dependiente de Carthago Nova, esto es dentro del ager carthaginensis parece evidente, igual que no debe ofrecer duda la relación de la Fortuna cartagenera con el topónimo de la población moderna y con el culto allí desarrollado. Hasta qué punto puede haber una dependencia de uno con respecto al otro, es una cuestión a dilucidar. Por otra parte, aún está por determinar de forma concluyente el culto o cultos vinculado con las inscripciones de la Cueva Negra, donde precisamente uno de los vocablos que más se repite en las inscripciones es el de antrum; en este sentido, no creo vano recordar aquí el culto oracular del santuario de Praeneste estrechamente vinculado al de la Fortuna Primigenia donde el pozo oracular de la terraza de los hemiciclos constituía el eje fundamental del culto. En cualquier caso las nuevas perspectivas que, en este aspecto, abre nuestra inscripción son muy sugerentes.

Finalmente, por cuestiones de espacio, no vamos a entrar aquí en profundidad en cuestiones relativas al programa decorativo integral del edificio, que claramente se puede relacionar con las inscripciones, ni en los posibles actos de evergetismo desarrollados por los sucesivos patronos nombrados por la ciudad, ya que todos estos análisis serán desarrollados in extenso en el corespondiente estudio global del edificio y de la excavación que en la actualidad se halla en avanzado estado de elaboración.

Todo ello entronca, en cualquier caso, con el proceso de urbanización y sobre todo de monumentalización de la ciudad en época augustea, fenómeno que se plasma sobre todo en la construcción de este magnifico edificio recordado en las inscripciones. El proceso coincide además con la concesión del patronato de la ciudad a importantes personajes de la vida política y militar del momento, muy vinculados por otra parte con la propia familia imperial, así como a miembros de esta misma. Destaca en este sentido, el carácter de pedestal de estatua que ofrecen las ins-

\footnotetext{
${ }^{80}$ Referencia tomada de González Blanco, A.: «Las inscripciones de Fortuna en la Historia de la religión romana. Perspectivas histórico religiosas». Ant. y Crist. IV, 1987, p. 297.

${ }^{81}$ Stylow, A.U. y Mayer, M.: «Los tituli de la Cueva Negra. Lectura y comentarios literario y paleográficon, Ant. y Crist. IV 1987 , pp. 191 y ss. y sobre todo 225-229.

${ }^{82}$ Sgobbo, I.: «Il maggior tempio del Foro di Cuma e la munificenza degli Heii cumani in epoca samnitica», Reendiconti della Accad. di Arch, Lett. e Belle Arti, 52, Nápoles, 1977, pp. 231-264
} 
cripciones conmemorativas de los nombramientos que sin duda, debieron estar ubicadas en un lugar importante, monumental y, por supuesto, público de la ciudad, construido o reconstruido con motivo de la concesión de su estatuto colonial ${ }^{\times 3}$. Por desgracia, no conocemos el emplazamiento original de estas inscripciones conmemorativas de patronato, aunque, paradójicamente, parte de su historia reciente ha estado vinculada con el entorno del Castillo de la Concepción. En este sentido quizás haya que contemplar este Cerro como uno de los puntos neurálgicos en el desarrollo de la ciudad. En cualquier caso, todo ello se enmarca, como ha señalado Roddaz en «un movimiento de proclamación de localismo con respecto a la familia imperial y traduce el cuidado de estas comunidades de entrar directamente en la clientela de ésta» ${ }^{84}$.

Es también, por otra parte interesante extrapolar esta situación de transformación urbana según cánones emanados desde la propia Roma a otras ciudades de clara raigambre púnica, de algún modo vinculadas a la propia Carthago Nova y que presentan un fenómeno de características similares. El ejemplo más significativo y próximo nos lo proporciona la ciudad de Cherchel donde durante el período de luba II, patrono de la ciudad hispana y su hijo Ptolomeo, Ilvir quinq. de la misma, se desarrolló un vasto programa edilicio, el más importante de toda la historia de la ciudad, que contempló la construcción de nuevos edificios como el teatro, foro, el llamado Palacio Real, templo de Isis, templo de Augusto, etc. ${ }^{85}$, donde muy probablemente participan talleres y arquitectos procedentes de la propia Urbe y donde aparece ampliamente documentado el uso del mármol blanco de las canteras de Luni. La vinculación arquitectónica y decorativa de los modelos emanados de la propia Roma, se manifiesta sobre todo en el caso concreto de los capiteles que adornan la escena del teatro de una y otra población, lejos ya de la tradición anterior de raíz púnica, que en el caso concreto de Carthago Nova se había manifestado en el amplio uso y particularidades que adoptó el orden jónico. Nos encontramos por primera vez en la ciudad con una decoración arquitectónica realizada, al menos parcialmente, en mármol blanco importado.

Los ejemplares de Cartagena presentan dos coronas de hojas de acanto que ocupan la mitad de la altura total del capitel. Las hojas de la primera corona se hallan divididas en cinco lóbulos, de los cuales los dos inferiores se dividen en cinco hojitas de forma lanceolada mientras que las de los dos centrales se articulan en seis, cuya unión determina la existencia de zonas de sombra en forma de gota alargada e inclinada, y el lóbulo superior en cinco. Fuerte y ancha nervadura central separada por dos profundas acanaladuras de los lóbulos laterales. Las hojas de la segunda corona nacen directamente de la base del kalathos. Los caulículos que brotan entre las hojas de esta segunda corona de hojas de acanto, presentan una forma estrecha, alargada y ligeramente inclinada con el tronco formado por cuatro hojas yuxtapuestas en forma de lengüeta rematadas en un grueso listel horizontal de sección cóncava. El cáliz está constituido por dos hojas de acanto de perfil, de tres lóbulos cada uno unidas entre si a través de las dos primeras

${ }^{83}$ Es muy curioso observar como este proceso de monumentalización cada vez mejor evidenciado a través de los vestigios arqueológicos de la ciudad coincide con la aparición sobre las monedas de la denominación oficial de la ciudad, fenómeno este que se produce, aunque la concesión de estatuto de ciudad privilegiada parece ser anterior, sólo con las emisiones postreras de Augusto. Lí única excepción la constituye la emisión con Palas y monumento de difícil ubicación cronológica.

${ }^{84}$ Roddaz, J.M. Marcus Agrippa. BEFAR, 253, 1984, p. 415.

${ }^{85}$ Pensabene, P.: «Les chapiteaux de Cherchel». Étude de la décoration architectonique. 3 Suppl. Bull. d'Archeologie Algérienne, 1982, especialmente pp. 69-73. 


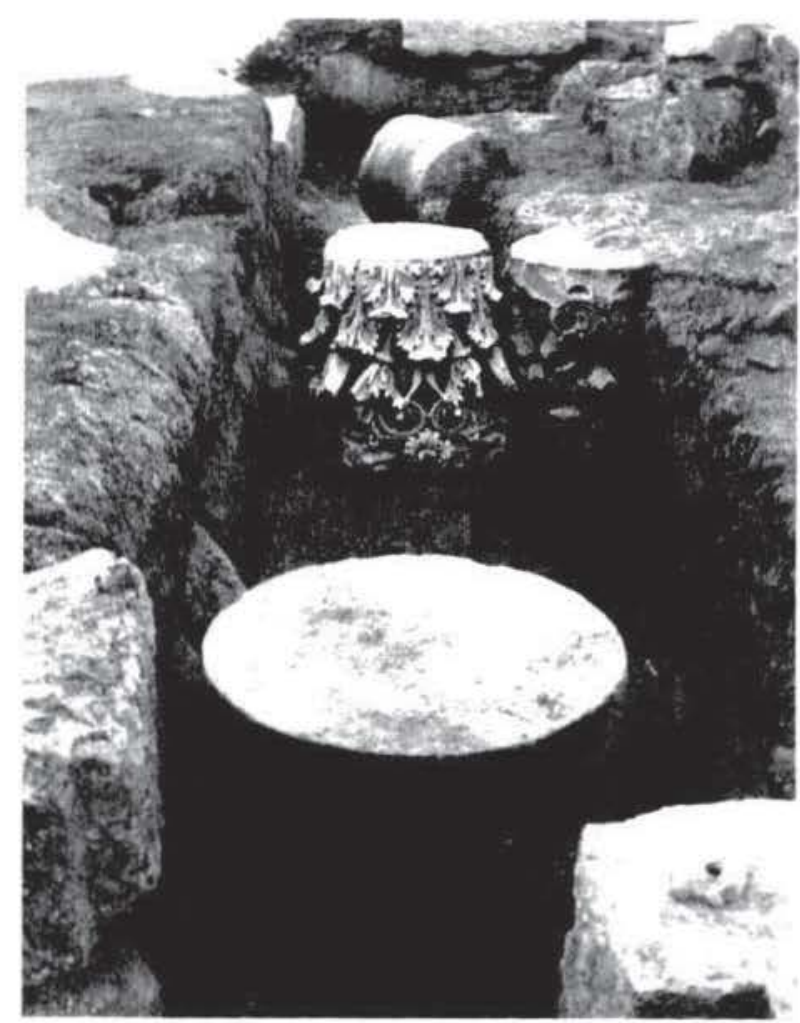

Fig. 11. Capiteles corintios reutilizados en las cimentaciones de las construcciones tardorromanas.

hojitas lanceoladas de los lóbulos inferiores que, determinan el característico y simétrico motivo en forma de triángulo. Su factura es idéntica a las de la mitad inferior. Volutas y hélices, en forma de cinta de sección cóncava se desarrollan desde el cáliz del caulículo y sostienen el ábaco. Las hélices aparecen unidas entre si por un listel. En el eje del capitel y sobre la hoja central de la segunda corona se desarrolla el cáliz formado por dos hojas lisas de perfil que entroncan con el extremo de las hojas de acanto del cáliz del caulículo, y desde donde nace el tallo apuntado y de sección circular de la flor del ábaco formada por abundantes pétalos y con un motivo serpentiforme en el centro. El ábaco de lados cóncavos apoya en los ángulos sobre las volutas y presenta el óvolo decorado con semiovas encerradas en esgucios y separadas por lancetas, y caveto liso. Entre las volutas y las hélices se desarrollan pequeñas rosetas de cuatro pétalos en torno a un botón central, que brotan de un tallo serpenteante pegado al kalathos y nacen de la unión de hélices y volutas. Es este un elemento ornamental característico de los capiteles itálicos del llamado "Grupo del Segundo Triunvirato" " ${ }^{* 6}$ que se manifiesta sobre todo en capiteles fechados entre los años 40-20 a.C. ${ }^{x 7}$ y pervive también, ya considerado como un rasgo arcaico. al menos hasta el cambio de Era. Los paralelos más significativos y mejor fechados nos los proporcionan capiteles procedentes de la basílica julia, fechado entre los años 40-22 a.C. ${ }^{\mathrm{x}}$, un ca-

*o Kähler, H.: Die Römischen Kapitelle des Rheingehietes, Berlín, 1959, pp. 77 y ss. y también, Heilmeyer, W.D.: «Korintische Normalkapitelle», MDAl, Ergz., 16, 1970, pp. 36-39.

${ }^{k 7}$ Strong, D.E. y Ward Perkins, J.B.: "The Temple of Castor in the Forum Romanun", PBSR. XXX. 1962 , p. 14.

${ }^{\mathrm{k} \times}$ Ward-Perkins, J.B. y Strong, 1962, p. 14 
pitel de pilastra del Foro Romano ${ }^{84}$, templo del Divo Iulio (año 29 a.C.) ${ }^{90}$, templo de Apolo Palatino, del año 28, ${ }^{91}$, un capitel de pilastra del Museo de Aquileia, con florecilla de ocho pétalos algo distinta a las anteriores, en un ejemplar fechado hacia finales del siglo I a.C. ${ }^{92}$, así como en los arcos de Rimini, Aosta y Susa, respectivamente fechados en los años 27, 25 y 9/8 a.C. ${ }^{93}$. Algo más tardíos, son los capiteles del templo de Cibeles sobre el Palatino, atribuidos a la restauración augustea del año 3 d.C., donde, según el editor, las florecillas entre hélices y volutas se manifiestan como la pervivencia de un rasgo más antiguo derivado de la tradición del segundo triunvirato ${ }^{44}$.

Fuera de Italia, hallamos este tipo de florecillas en los capiteles del frons scaena del teatro de Arles, fechados seguramente entre los años 20-10 a.C., asociados a un tipo de acanto de corte simétrico ${ }^{95}$.

También en la Península Ibérica, una gran parte de los capiteles fechados a finales de la República o en los primeros años augusteos, tallados sobre piedra local, presenta esta florecilla entre volutas y hélices ${ }^{46}$. Los paralelos más próximos nos los ofrecen un capitel del Museo de Historia de la Ciudad de Barcelona, pero sobre todo cuatro ejemplares procedentes del área del entorno del teatro de Tarragona con una concepción global muy similar a las de Cartagena, aunque trabajadas sobre areniscas ${ }^{97}$. Este paralelismo se aprecia también con los capiteles de pilastra del arco de Bará, fechados recientemente a finales del siglo I a.C., datación que concuerda plenamente con la cronología de Cartagena ${ }^{98}$.

En general, de concepción similar es un capitel reutilizado en el templo de S. Angelo de Perugia, aunque sin las florecillas de cuatro pétalos, pero con la flor del ábaco en forma de margarita y con motivo vegetal serpentiforme en el centro y doble corona de hojas de acanto de ca-

"No Ward-Perkins, J.B.: An early Augustan Capital in the Forum Romanum. PBSR, XXXV, 1967, pp. 23-28. El autor plantea la posibilidad de que estos fragmentos puedan pertenecer a la primera edificación de la basílica Iulia, o también a la reconstrucción del templo de Saturno debida a L. Munatius Plancus, en cualquier caso a un edificio de la primera mitad del reinado augusteo.

${ }^{90}$ Kähler, op. cit. 1939

${ }^{91}$ Bauer, H.: "Das Kapitell des Apollo Palatinus-Tempels". MDAI (R), 76, 1969, pp. 183 y ss., especialmente fig. 4

${ }^{92}$ Reproducido en la lám. 64, 4 del artículo de Bauer arriba citado.

${ }_{93}^{93}$ De Maria, 1979, y 1977. Para el de Susa, Maria, S. de: "Apparato figurativo nell'arco onorario di Susa. Revisione critica del problema". Rivista di Archeologia, 1, 1977, pp. 44-52.

${ }^{94}$ Pensabene, P.: "Quinta campagna di scavo nell'area sudoest del Palatino", Archeologia Laziale, V, 1983, p. 72, ff. 4 y 8-12. Para la pervivencia de rasgos especificos de capiteles de inicios del siglo I a.C. en capiteles de los inicios de la época augustea, vid. von Hesberg, H.: Lo sviluppo dell'ordine corinzio in età tardorepublicana. L'art decoratif à Rome, EFR, 55, 1985, p. 21.

${ }^{95}$ Roth-Conges, A.: L'acanthe dans le décor architectonique protoaugustéen en Provence, $R A N, 16$, 1983, especialmente nota 71.

${ }^{96}$ Gutiérrez, M.A.: Sobre la sistematización del capitel corintio en la Península Ibérica. BSEAA, XLVIII-Valladolid,

${ }^{97}$ Recasens, M.: "Los edificios públicos de la Tarragona romana a través del estudio de sus capiteles: ensayo cronológico". I Jornadas de Arqueología Romana, Granollers, 1987, pp. 321-340, concretamente los números 1-6, en su mayor parte datados, excepto el primero de época tardo-republicana, hacia finales del siglo I a.C. o inicios del siglo I d.C.

${ }^{98}$ Dupre, X.: "Els capitells corintis de l'arc de Berà (Roda de Berà, Tarragonés)». Empúries, 45-46, 1983-1984, pp. 308-315. 
racterísticas semejantes a las de Cartagena, datado hacia la media-edad augustea ${ }^{\%}$. El mismo florón del ábaco con motivo serpentiforme se reproduce también sobre un capitel de Ostia (R.I,Is.XII,6), con hélices de cinta de sección ligeramente cóncava unidas entre si por un listel y tallo de sección cilíndrica que brota desde un sencillo cáliz ${ }^{1(x)}$. Algunos elementos, tales como la forma de los caulículos e incluso también el tratamiento de las hojas de acanto remite asimismo a un capitel procedente de esta misma ciudad (R.I, Is. XII,1), datado en época tardo-augustea o más bien en la primera edad julio-claudia ${ }^{101}$.

La decoración del óvolo con un kyma jónico de ovas separadas por lancetas es también frecuente en capiteles de la primera época imperial y en ámbitos occidentales especialmente en la época julio-claudia ${ }^{102}$ si bien es un elemento que se manifiesta en capiteles corintios del Oriente Mediterráneo en épocas bastante posteriores ${ }^{103}$. En el primer caso se presenta en los capiteles del arco de los Sergios, construido en torno a los años 29-28 a.C. con lengüetas sobre el cavetto, en el templo de Apolo Sosiano con ligeras variantes respecto al anterior, así como en el Templo de los Castores de Roma, datado en el año 6 d.C. y, ya fuera de Roma, en los capiteles de la escena del teatro de Arles ubicados en la segunda decena a.C. ${ }^{104}$, o en un conjunto de cinco capiteles de Saintes Antiques con florecillas de cuatro pétalos en los espacios entre hélices y volutas y con acanto espinoso que caracteriza en Roma al denominado «Grupo del Segundo Triunvirato" arriba mencionado ${ }^{105}$ y sobre todo los capiteles de la Maison Carrée fechados ahora en época medio-augustea ${ }^{106}$ por citar algunos de los ejemplos más conocidos. La misma decoración hallamos de nuevo en capiteles compuestos del frons scaena del teatro de Ostia datados en torno al año 12 a.C. ${ }^{107}$.

Respecto a los caulículos, su composición y forma, ligeramente inclinada, con las estrías sobre el tronco verticales y el grueso listel horizontal cóncavo en el extremo superior nos remiten de nuevo al Templo de Castor arriba citado pero sobre todo a los caulículos del templo de Mars Ultor del Foro de Augusto, dedicado en el año 2 a.C. ${ }^{10 \times}$ y a una amplia serie de ejemplares de él directamente derivados. Podríamos destacar, entre ellos, de nuevo los caulículos de los capiteles de la Maison Carrée, donde, asimismo, las dos hojas de acanto que brotan del tronco, dispuestas de perfil, presentan la misma forma y responden seguramente al mismo modelo. Nuevas concomitancias, fruto más de la derivación de un modelo común que de una relación directa, hallamos con estos capiteles nimenses en el corto listel que une las hélices y bajo el cual asciende el tallo del florón del ábaco, ligeramente fusiforme y engrosado en el extremo inferior,

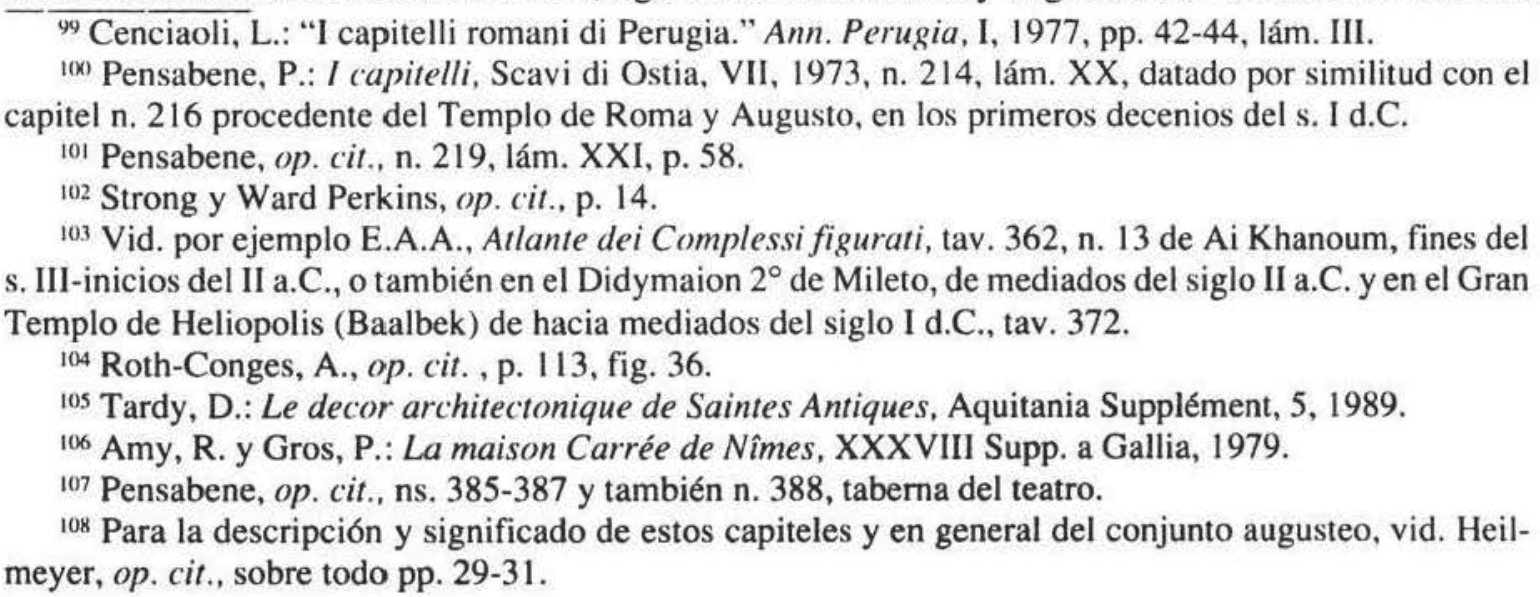


dotado asimismo de un pistilo serpentiforme de características similares a los de Cartagena, aunque, por otro lado, mucho más próximos a los mismos prototipos del templo de Marte del Foro de Augusto. El cáliz es, en cierto modo, una esquematización de aquél y se halla muy próximo al capitel $3 \mathrm{~W}$ de Nimes ${ }^{(1 \times)}$

En cuanto a las hojas de acanto destaca, en primer lugar, el corte disimétrico que determinan las digitaciones de los distintos lóbulos de las dos coronas de hojas al conectarse entre sí, creando unas zonas de sombra en forma de gota alargada y que, aproximadamente desde el cambio de Era, caracteriza al acanto de época imperial frente al tipo de acanto de corte simétrico propio de época tardo republicana, cuyos ejemplos bien datados más recientes se ubican en el último decenio a.C. y hacia el cambio de Era " ${ }^{110}$. Las referencias estilísticas nos conducen de nuevo a algunos de los capiteles de la basílica Emilia y al templo de Roma y Augusto de Ostia, ambos de cronología algo posterior a los de Cartagena, donde algunas digitaciones, al igual que sucede ya en los capiteles del templo de Marte, y a diferencia de Cartagena, llegan a solaparse ligeramente. Por otra parte, la forma de la hojas recuerda también algunos de los capiteles de la Maison Carrée, realizados, según Gros, por artesanos locales inspirados en los cartones de los capiteles del templo de Mars Ultor, pero conservando incluso algunas tradiciones locales que individualizan este conjunto, fechado en época medio augustea y concretamente antes de los años 5-6 d.C., frente a sus modelos "'".

Nos encontramos, en definitiva, ante capiteles que globalmente entroncan con la tradición de los talleres medio augusteos de la propia Roma, tradición visible en el modelado, la tendencia naturalística de las hojas de acanto, la plasticidad y carnosidad de los lóbulos suavemente inclinados y ahuecados en el centro, la forma de los caulículos, florón del ábaco, etc., pero que al mismo tiempo remiten aún, en cuanto a la decoración de pequeñas flores de cuatro pétalos situadas entre las volutas y las hélices, a los capiteles del denominado "Grupo del Segundo Triunvirato", de cronología anterior.

Estilísticamente, sus rasgos concuerdan básicamente con la datación ofrecida por las inscripciones arriba comentadas (5 a.C.-1 d.C.), realizadas además en el mismo material, cuyo empleo en cantidad aparece así atestiguado por primera vez, introducido seguramente por artesanos griegos en parte e inicialmente activos en talleres de la propia capital.

De esta forma, la construcción de este edificio se enmarcaría en un vasto proceso de urbanización que afecta a un gran número de ciudades del Imperio y que contempla entre otros aspectos, y junto a la restauración o construcción de las murallas, la erección del teatro ${ }^{112}$. En el

\footnotetext{
${ }^{109}$ Amy y Gros, op. cit. lám. 58b.

${ }^{110}$ Roth-Congès, op. cit., son según esta autora los capiteles del arco de Susa, fechado por una inscripción entre los años 9-8 a.C., del templo de la Fortuna de Pompeya, c. 3 a.C. y del templo de la Magna Mater, en el Palatino, reconstruido hacia el 3 d.C.

III Amy y Gros, op. cit. pp. 144-145.

${ }^{112}$ La utilización de estos edificios como centro de expresión de la fidelidad a la casa imperial con numerosas estatuas e imágenes de la familia reinante, ha sido planteada por Bejor, G.: "L'edificio teatrale nell'urbanizzazione augustea", Athenaeum, 57, 1979, pp. 124-138. En este mismo sentido, P. Gros ha insistido sobre el alto contenido político e ideológico de estos altares dedicados a los Caesares, enmarcados frecuentemente en vastos programas urbanísticos y ubicados en sitios especialmente significativos en la topografía e historia de la ciudad, poniéndolos en relación con la instauración de un primer culto de carácter dinástico que precedería al culto imperial propiamente dicho. Vid. Gros, P., op. cit., y también, "Un
} 
caso concreto de Cartagena es curioso observar cómo este proceso coincide además con la introducción regular del topónimo de la ciudad en las monedas donde se expresa de forma clara la titulación de Colonia Urbs Nora Carthago, fenómeno que coincide seguramente con un momento en el que la ciudad comienza a abandonar su viejo aspecto de ciudad republicana, condicionada hasta entonces por la impronta púnica para convertirse, como cada vez más traducen los nuevos hallazgos, en una ciudad de aspecto completamente nuevo. Esta transformación se prolongará seguramente durante la época julio-claudia, momento de mayor auge de la ciudad como capital del Conventus Carthaginensis.

programme augustéen: le centre monumental de la colonie d'Arles, " $J d I, 102,1987$, pp. 339-363, y más recientemente, "Nouveau paysage urbain et cultes dynastiques: remarques sur l'idèologie de la ville augustéenne a partir des centres monumentaux d'Athènes, Thasos, Arles et Nimes». In: Les villes augustéenne de Gaule, Colloque d'Autun, 6-8 juni, 1985, (Aunt, 1991), pp. 127-140. Hasta que punto hay que relacionar estas aras y las inscripciones arriba mencionadas con la pronta erección del templo dedicado a Augusto reproducido en las monedas de Carthago Nova, es algo que habrá que determinar con la intensificación de los trabajos de campo y sobre todo con la revisión de los materiales ya existentes. 